\title{
A Retail Benchmarking Approach to Efficient Two-Way Access Pricing*†
}

\author{
Doh-Shin Jeon ${ }^{\ddagger} \quad$ Sjaak Hurkens ${ }^{\S}$
}

October 31, 2007

\begin{abstract}
We study a retail benchmarking approach to determine access prices for interconnected networks. Instead of considering fixed access charges as in the existing literature, we study access pricing rules that determine the access price that network $i$ pays to network $j$ as a linear function of the marginal costs and the retail prices set by both networks. In the case of competition in linear prices, we show that there is a unique linear rule that implements the Ramsey outcome as the unique equilibrium, independently of the underlying demand conditions. In the case of competition in two-part tariffs, we consider a class of access pricing rules, similar to the optimal one under linear prices but based on average retail prices. We show that firms choose the variable price equal to the marginal cost under this class of rules. Therefore, the regulator (or the competition authority) can choose one among the rules to pursue additional objectives such as consumer surplus, network coverage or investment: for instance, we show that both static and dynamic efficiency can be achieved at the same time.
\end{abstract}

Keywords: Networks, Access Pricing, Interconnection, Competition Policy, Telecommunications, Investment

JEL numbers: D4, K21, L41, L51, L96

\footnotetext{
*This paper extends and replaces Jeon (2005) which exclusively focussed on competition in linear prices.

${ }^{\dagger}$ We thank the seminar participants at the Kiel-Munich workshop on economics of information and network industries 05, EARIE 05, KISDI, IAE, Competition and Regulation Conference at Corfu 07, ESEM 07, and IDEI/Bruegel conference on Regulation, Competition, and Investment in Network Industries 07. We also thank Mark Armstrong, Tommaso Valletti, Xavier Vives and Julian Wright for useful comments. Jeon gratefully acknowledges the financial support from the Spanish government under SEJ2006-09993/ECON and Ramon y Cajal grant. Hurkens gratefully acknowledges the financial support from the Spanish Ministry of Science and Technology under SEJ2006-01717. Both authors acknowledge support through grant CONSOLIDER-INGENIO 2010 (CSD2006-00016) and through the NET Institute www.NETinst.org.

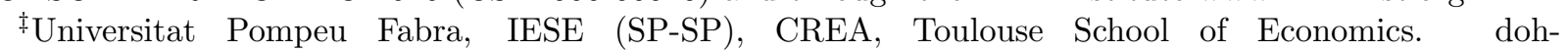
shin.jeon@upf.edu

§Institute for Economic Analysis (CSIC) and CREA, Bellaterra, Spain. sjaak.hurkens@iae.csic.es.
} 


\section{Introduction}

Access pricing constitutes the core of the policy issues regarding interconnected networks. More precisely, studying how access prices affect competition between networks and determining the optimal access prices form the central questions of the seminal papers on two-way network interconnection in Telecommunication Industry (Armstrong 1998, LaffontRey-Tirole (LRT, hereafter), 1998a,b) and the papers that followed. ${ }^{1}$ Although the papers vary in terms of the retail prices they consider (linear versus non-linear prices, with or without network based price discrimination), the degree of customer heterogeneity and whether or not they explicitly consider receivers' surplus, all the papers have a common trait in that they consider a fixed access price, which is either negotiated bilaterally between two networks or is fixed by a regulatory agency. In this paper, we make a departure from this standard approach and consider what we call a retail benchmarking approach. In our approach, we study access pricing rules that determine the access price that network $i$ pays to network $j$ as a (linear) function of the marginal costs and the retail prices set by both networks. We first consider the case of competition in linear prices and derive the optimal access pricing rule within the class of linear rules. Then we consider the case of competition in two-part tariffs and study an adaptation of the optimal rule we discovered in the previous case. It turns out that both rules have some remarkable properties that we explain below.

Although most of the literature on two-way access pricing has moved on from linear prices to non-linear prices, in this paper we consider both competition in linear prices and in two-part tariffs, as we think that both of them are relevant. In particular in mobile telecommunication markets, it is not uncommon for firms to set linear prices by means of prepaid cards. In 2005, almost half of 40 million mobile phone users in Spain had prepaid cards. Moreover, many operators in Spain offer consumers contracts with a linear price and no subscription fee (but with a minimum amount charged monthly). Such contracts are very much like linear prices. The most recent entrant in the Spanish mobile telecommunication market, Yoigo, in fact only offers uniform linear prices without subscription fees, without minimum consumption requirements and without network based price discrimination.

In the case of competition in linear prices, we consider a set of linear access pricing rules that includes any fixed access price and the well-known Efficient Component Pricing Rule (ECPR) as particular rules. We show that within this set, there is a unique rule that

\footnotetext{
${ }^{1}$ See, for instances, Carter and Wright (1999, 2003), Dessein (2003), Gans and King (2000, 2001), Hahn (2004), Hermalin and Katz (2001, 2004), Jeon-Laffont-Tirole (2004), Laffont-Marcus-Rey-Tirole (2003), Valletti and Cambini (2005) and Wright (2002).
} 
implements the Ramsey outcome as the unique equilibrium, independently of the underlying demand conditions, as long as there exists at least a mild degree of substitutability between networks' services. This optimal rule is such that the mark-up of the access price that network $i$ pays to network $j$ is equal to the mark-up of network $i$ 's retail price multiplied by $n /(n-1)$ where $n$ represents the number of competing networks. This rule promotes competition in retail prices as network $i$ can decrease its access payment by reducing its retail price. Since access pricing rules are much more general than fixed access prices, it is perhaps not that surprising that some rule is able to implement the Ramsey outcome. What is a very remarkable feature of the optimal access pricing rule is that it does not depend on the demand structure ${ }^{2}$ so that the regulator only needs to observe marginal costs and retail prices and does not need to know anything about the demand side. ${ }^{3}$ Furthermore, our model and access pricing rules allow for more than two competing networks. ${ }^{4}$

In the case of competition in two-part tariffs, we adapt the access pricing rule that is optimal in the case of linear prices such that the mark-up of the access price above the termination cost that network $i$ pays to network $j$ is equal to network $i$ 's average retail price mark-up multiplied by a factor $\kappa .{ }^{5}$ We show that under the adapted rules each network finds it optimal to charge its variable price equal to the true marginal cost for any market share and for any $\kappa \leq 1$ : in fact, when $\kappa=0$, the access price is equal to the termination cost and LRT (1998a) show that in this case, the variable price is equal to the marginal cost. When $\kappa=0$, network $i$ 's profit is equal to its market share multiplied by profit per customer (net of the fixed cost per customer). Therefore, maximizing network $i$ 's profit with respect to its variable price, while maintaining its market share constant, is equivalent to maximizing its profit per customer, which leads to the marginal cost pricing. When $\kappa \neq 0$, under our access

\footnotetext{
${ }^{2}$ Under the LRT assumption of full coverage

${ }^{3}$ In contrast, under the standard approach of fixed access price (LRT,1998a), (i) the Ramsey access price must be lower than the termination cost but no equilibrium exists if the access price is different from the termination cost and the services provided by different networks are substitutable enough; (ii) if access prices are determined through private negotiations, networks can achieve the monopoly outcome by coordinating on a certain level of access price; (iii) the Ramsey access price is informationally demanding since it requires the regulator to possess precise information regarding both the cost and the demand structure.

${ }^{4}$ Stennek and Tangerås (2006) also consider a model that allows for more than two networks. Their analysis accounts for the fact that the bilaterally agreed upon fixed access price between two networks affects their competitiveness with respect to other rivals in a setting with linear retail prices. Since network based price discrimination is not allowed for in the model, the equilibrium retail price set by one particular network will be influenced by all negotiated access prices. It is shown that, in the absence of regulation, this competition in access prices has no effect and networks will be able to sustain monopoly retail prices. However, a light-handed form a regulation (setting a maximum access price) induces networks to set retail prices close to marginal cost when networks are sufficiently close substitutes.

${ }^{5}$ It turns out that the rule that implements the Ramsey outcome in case of linear prices gives firms incentives to set variable price below cost and high fixed fees, generating a high volume of (off-net) calls for which negative access charges would have to be paid.
} 
rule, the access payment per customer that network $i$ makes to its rival networks is equal to a fraction (smaller than one) of its profit per customer (as long as $\kappa \leq 1$ ). Therefore, our rule generates the marginal cost pricing as long as $\kappa=0$ does it. We show that this result is robust: for instances, it holds when networks are asymmetric (either in terms of quality of their networks or customer brand loyalty) or when networks face heterogeneous customers and compete with a menu of non-linear tariffs.

Therefore, the competition authority can properly choose $\kappa$ to pursue another goal while achieving the efficient pricing in terms of variable price. For instance, since the equilibrium profit decreases with $\kappa$ (i.e., the profit neutrality result does not hold within our framework), $\kappa$ can be chosen to increase consumer surplus at the expense of firms' profits. This also suggests that $\kappa$ can be chosen to promote penetration in markets where no full coverage equilibrium exists with fixed access charges. Very interestingly, $\kappa$ can also be chosen to increase firms' profits so as to create incentives for socially optimal investment in network quality (i.e., to achieve static and dynamic efficiency at the same time).

Making access prices depend on retail prices is an old idea in the case of one-way access. The well-known $\mathrm{ECPR}^{6}$ achieves the efficient entry by equalizing the access price that an entrant should pay to the incumbent with the sum of the cost of providing the access and the latter's opportunity cost (i.e., the incumbent's retail price mark-up) when the incumbent's retail price is regulated. However, the ECPR is not good at promoting competition in retail prices when the retail prices are not regulated since the access price that the incumbent receives increases with its retail price. ${ }^{7}$ This motivated Sibley et al. (2004) to consider the Generalized Efficient Component Pricing Rule (GECPR) in which the access price that an entrant pays is, roughly speaking, equal to the sum of the cost of providing the access and the entrant's opportunity cost (i.e., the entrant's retail price mark-up). They find that since the entrant can reduce its access charge payment by lowering its retail price, the GECPR is good at intensifying retail competition.

In the case of two-way access, LRT (1998a) examine various interpretations of the ECPR in a duopoly framework and show that when networks can privately negotiate on a fixed level of access price, the ECPR allows them to collude and achieve the monopoly outcome. More importantly, Mialon (2007) studies the GECPR, considered by Sibley et al. (2004) in

\footnotetext{
${ }^{6}$ See Baumol (1983), Baumol and Sidak (1994) and Willig (1979). For an introduction to the ECPR, see Armstrong (2002) and Laffont and Tirole (2000).

${ }^{7}$ Moreover, as Economides and White (1995) point out, the ECPR avoids entry by less efficient entrants and thus achieves productive efficiency, but this social gain may be more than outweighed by the loss in consumer surplus by means of foregone competition and high retail prices.
} 
one-way access, in LRT's framework of duopoly with linear pricing. ${ }^{8}$ Under the GECPR, the mark-up of the access price that network $i$ pays to the rival network is equal to the former's retail price mark-up. We show that there exists a unique rule achieving the Ramsey outcome in the set of linear access pricing rules which includes the GECPR as a special case. Since the optimal rule is different from the GECPR, the GECPR does not achieve the Ramsey outcome. ${ }^{9}$

In practice, there are cases in which access prices (or termination charges) are linked to average retail prices. Some countries use a "retail-minus" approach to set access prices on the basis of a fixed discount off the corresponding retail prices. (See OECD, 2004.) Another example of pegging access price to retail tariffs can be found in the international postal service. For instance, access prices (i.e., what they call "termination dues") among European countries should be set at $80 \%$ of domestic tariffs (Ghosal, 2002). In the context of termination charges for mobile phone service, the Australian Competition and Consumer Commission (2001) adopted what they call a "retail benchmarking approach", which means that "access prices for GSM termination will fall at the same rate as retail prices for mobile services provided by a mobile carrier (p.89)." However, the ACCC retail benchmarking approach is different from ours in several respects. The most important difference is that the ACCC linked the access price charged by an operator to the average retail price of the same operator, similar to what occurs in the ECPR. The ACCC recognized that this could potentially give disincentives to lower retail prices (p. 75), as we explained above. However, the ACCC relied on the competitive pressure in the retail market to continue retail price reductions observed in previous years, which would then imply access price reductions, which in turn could reinforce lower retail prices. In 2004 the ACCC abandoned their retail benchmarking approach, mainly because retail prices had in fact not (significantly) decreased in the period 2001-2004. ${ }^{10}$ Another difference between the ACCC approach and our proposal is that the ACCC considered intertemporal linkages (access prices in the next six month period depend on retail prices reductions in the last six month period) whereas we consider instantaneous linkages. A final difference with our rule is that we propose to benchmark retail and access price mark-ups, whereas the ACCC benchmarked absolute retail and access

\footnotetext{
${ }^{8}$ Doganoglu and Tauman (2002) also consider a linear access pricing rule which depends on retail price. More precisely, in their paper, the access price that network $i$ receives from network $j$ is a (positive and) constant fraction of the linear retail price that network $i$ charges. This rule is included as a special case in the set of the access pricing rules that we consider. As is explained in section 3 , this kind of rule cannot be optimal since network $i$ has an incentive to increase (rather than reduce) its retail price in order to receive a higher access payment.

${ }^{9}$ In fact, the equilibrium price under the GECPR is higher than the Ramsey price.

${ }^{10}$ See, ACCC (2004).
} 
prices.

Our result in Section 4 that there is a class of access pricing rules which achieve efficiency when networks face heterogeneous consumers and compete in menus of two-part tariffs is interesting in its own right. Previously, Dessein (2003) and Hahn (2004) find that when the access price is equal to the termination cost (i.e., $\kappa=0$ ), network competition achieves efficiency. However, in this case, access price disappears from the profit function and the profit function becomes the same as the one in a standard Hotelling model without interconnection. This is why they rediscover the efficient two-part tariff result obtained by Armstrong and Vickers (2001) and Rochet and Stole (2002) in the context of competitive price discrimination without interconnection. In other words, in Dessein (2003) and Hahn (2004), efficiency is achieved by making the case with interconnection similar to the case without interconnection. What we show is that in the presence of interconnection, there is a class of access pricing rules which achieve efficiency; interconnection provides additional instruments to achieve efficiency with respect to no interconnection.

Section 2 presents the general model, defines the set of linear access pricing rules and characterizes the Ramsey outcome. Section 3 considers competition in linear prices: it first establishes the main result, compares different access pricing rules and discusses the robustness of the result to relaxing the full coverage assumption. Section 4 considers how the rule can be adapted in a context where firms compete in two-part tariffs by benchmarking the access price to the average retail price. Section 4.1 shows that a whole class of benchmarking rules lead to marginal cost pricing. Section 4.2 studies how the regulator (or the competition authority) can achieve additional goal(s) such as optimal investment by adequately choosing among these rules and also shows that the marginal cost pricing result of section 4.1 holds even when we consider heterogeneous consumers or asymmetric networks. Section 5 concludes. All the proofs except that of Proposition 2 are gathered in the Appendix.

\section{Framework}

\subsection{The model}

We present a general model of $n$-network competition which includes the duopoly model of LRT (1998a) as a special case. There is a mass one of consumers.

\section{- Individual demand:}

Let $u(q)$ be the utility that a consumer derives from placing $q$ volume of calls. The utility 
function $u(\cdot)$ is twice continuously differentiable, with $u^{\prime}>0, u^{\prime \prime}<0$, which implies that demand function is differentiable. Let $q(\cdot)$ denote the demand function, given by $u^{\prime}(q(p))=p$ where $p$ is the variable retail price. When network charges $p_{i}$, the volume of calls placed by a customer of network $i$ is given by $q\left(p_{i}\right)$. Let $v(p)$ be the indirect utility function, i.e.,

$$
v(p)=\max _{q}\{u(q)-p q\}
$$

Let $R(p) \equiv(p-c) q(p)$ represent the revenue per consumer. We assume that $R(p)$ has a unique maximum at $p=p^{m}$, is strictly increasing when $p<p^{m}$ and strictly decreasing when $p>p^{m}$. Therefore, $p^{m}$ denotes the monopoly price. Let $R^{m}$ denote the monopoly revenue per consumer (i.e., $R^{m}=R\left(p^{m}\right)$ ). We assume $\lim _{p \rightarrow \infty} R(p)=0$.

- Firm's demand (or market share):

The networks (i.e., firms) provide horizontally differentiated services and each network can cover all the consumers. Consider first competition in two-part tariffs: firm $i$ chooses tariff $T_{i}=F_{i}+p_{i} q$. Given $\left(p_{i}, F_{i}\right)$, the net surplus of a consumer of network $i$ is given by:

$$
w_{i}=v\left(p_{i}\right)-F_{i}
$$

Let $\mathbf{w} \equiv\left(w_{1}, \ldots w_{n}\right)$ and $\mathbf{w}_{-i} \equiv\left(w_{1}, . ., w_{i-1}, w_{i+1}, \ldots, w_{n}\right)$. Let $\alpha_{i}\left(w_{i} ; \mathbf{w}_{-i}\right)$ denote the measure of consumers subscribing to network $i$. We assume that $\alpha_{i}(\mathbf{w})$ satisfies the following properties:

Property 1 (symmetry): For any vector $\mathbf{w}$ with $w_{i}=w_{j}$ for some $i$ and $j$, we have $\alpha_{i}(\mathbf{w})=\alpha_{j}(\mathbf{w})$.

Property 2 (monotonicity): For any $i, j=1, \ldots, n$ and $i \neq j, \alpha_{i}\left(w_{i} ; \mathbf{w}_{-i}\right)$ is differentiable with respect to $w_{i}$ and each $w_{j}$ and increases with $w_{i}$ and decreases with $w_{j}$; it strictly increases with $w_{i}$ and strictly decreases with $w_{j}$ for $\alpha_{i} \in(0,1) .{ }^{11}$

Property 3 (full coverage): $\sum_{i=1}^{n} \alpha_{i}\left(w_{i} ; \mathbf{w}_{-i}\right)=1$ for all relevant $\mathbf{w} \in \Re_{+}^{n}$.

Properties 1, 2, and 3 are satisfied by the Hotelling model of LRT (1998a) and the circular city model with $n=2$ or 3 (Salop, 1979). For $n>3$, our model is more natural

\footnotetext{
${ }^{11}$ Property 2 can be more rigorously defined as follows. Given $\mathbf{w}_{-i}$, let $\bar{w}_{i}$ be the minimum $w_{i}$ making $\alpha_{i}\left(w_{i} ; \mathbf{w}_{-i}\right)=1$ and let $\underline{w}_{i}$ be the maximum $w_{i} \in \Re_{+}$making $\alpha_{i}\left(w_{i} ; \mathbf{w}_{-i}\right)=0$. Then, $\alpha_{i}$ strictly increases with $w_{i}$ for $w_{i} \in\left[\underline{w}_{i}, \bar{w}_{i}\right]$. Similarly, given $\mathbf{w}_{-j}$ with $j \neq i$, let $\bar{w}_{j}$ be the minimum $w_{j} \in \Re_{+}$making $\alpha_{i}\left(w_{i} ; \mathbf{w}_{-i}\right)=0$ and let $\underline{w}_{j}$ be the maximum $w_{j} \in \Re_{+}$making $\alpha_{i}\left(w_{i} ; \mathbf{w}_{-i}\right)=1$. Then, $\alpha_{i}$ strictly decreases with $w_{j}$ for $w_{j} \in\left[\underline{w}_{j}, \bar{w}_{j}\right]$.
} 
than the circular city model since in the latter, a (minor) price change of network $i$ affects only the demands of its direct neighbors (network $i-1$ and network $i+1$ ) but does not affect the demands of other networks. In the context of telecommunication markets all networks compete directly with each other for all customers, and not only with two artificial "neighbors" for a specific subset of consumers. The symmetry and the full coverage imply $\alpha_{i}=\frac{1}{n}$ for all $i=1, \ldots, n$ if $w_{i}=w$ for all $i=1, \ldots, n$. Regarding the full coverage property, LRT (1998a) assume that each consumer derives, in addition to $u(q)$, a constant utility $v_{0}$ from subscribing to one of the networks, which is large enough to ensure that all consumers always choose to join one of the networks. Since the total mass of consumers is equal to one, under full coverage, the mass of consumers subscribing to network $i$ (i.e., $\alpha_{i}$ ) is equal to network $i$ 's market share.

In the case of competition in linear prices, let $\mathbf{p} \equiv\left(p_{1}, \ldots, p_{n}\right) \in \Re_{+}^{n}$ represent the vector of retail prices and let $\mathbf{p}_{-i} \equiv\left(p_{1}, . ., p_{i-1}, p_{i+1}, \ldots, p_{n}\right)$. Since $w_{i}$ strictly decreases with $p_{i}$, it is more convenient to work with $\alpha_{i}\left(p_{i} ; \mathbf{p}_{-i}\right)$ than with $\alpha_{i}\left(w_{i} ; \mathbf{w}_{-i}\right)$. Obviously, properties 1-3 imply that similar properties hold for $\alpha_{i}\left(p_{i} ; \mathbf{p}_{-i}\right)$. Of course, $\alpha_{i}\left(p_{i} ; \mathbf{p}_{-i}\right)$ decreases with $p_{i}$ and increases with $p_{j}$.

- Cost:

Concerning the cost side, we use the same technology that is used in LRT (1998a). Serving a customer involves a fixed cost $f>0$, say of connecting the customer's home to the network and of billing and serving her. We assume $R^{m}>f$. A network also incurs a marginal cost $c_{0} \geq 0$ per call at the originating and terminating ends of the call and marginal cost $c_{1} \geq 0$ in between. Therefore, the total marginal cost of a call is

$$
c \equiv 2 c_{0}+c_{1}>0
$$

\subsection{Access pricing rules}

We consider simple access pricing rules which are not informationally demanding. More precisely, the informational constraint that the regulator faces is defined as follows.

- The regulator's informational constraint:

On the one hand, we assume that the regulator (or the competition authority) has limited information about the market such that she is not informed about the individual demand 
function $q(p)$, each firm's demand function and the value of the fixed cost $f$. On the other hand, she knows the marginal cost $c$ and the termination cost $c_{0}$. Furthermore, she and consumers observe retail prices $\left(p_{1}, \ldots, p_{n}\right)$ or $\left[\left(p_{1}, F_{1}\right), \ldots,\left(p_{n}, F_{n}\right)\right]$. Moreover, when we consider competition in two-part tariffs, we need to assume that the regulator can observe average retail prices, ${ }^{12}$ which means that she must be able to observe realized demand.

The firms are assumed to know all the relevant information regarding both the demand and the cost sides.

\section{- The linear access pricing rules:}

Let $a_{i j}$ with $i \neq j$ denote the access charge that network $i$ pays to network $j$. Consider competition in linear prices. In order to consider simple rules, we limit our attention to the following linear access pricing rules:

$$
a_{i j}-c_{0}=h\left(p_{i}, p_{j}, c\right)=h_{1} p_{i}+h_{2} p_{j}+h_{3} c+h_{4} \text { for any } i, j=1, \ldots, n \text { and } i \neq j,
$$

where $\left(h_{1}, h_{2}, h_{3}, h_{4}\right) \in \Re^{4}$ is a vector of constants. Note that we consider a reciprocal access pricing rule since the coefficients $\left(h_{1}, h_{2}, h_{3}, h_{4}\right)$ do not depend on firms' identities. This is without loss of generality given that we consider symmetric networks. ${ }^{13}$ Let $\Lambda_{n}^{L}$ be the set of linear access pricing rules satisfying the above form (1). Some special cases of linear access pricing rules are:

- Cost based access pricing rule: $a_{i j}=c_{0}$.

- Efficient component pricing rule (ECPR): $a_{i j}-c_{0}=p_{j}-c$.

- Generalized efficient component pricing rule (GECPR): $a_{i j}-c_{0}=p_{i}-c$.

- Bill and keep: $a_{i j}=0$.

In the case of the ECPR, the access price that network $i$ pays to network $j$ is the sum of the termination cost and network $j$ 's retail price mark-up. In contrast, in the case of the GECPR, the access price that network $i$ pays to network $j$ is the sum of the termination cost and network $i$ 's retail price mark-up (Sibley et al. 2004, Mialon 2007).

\footnotetext{
${ }^{12}$ For instance, the Spanish telecommunication agency (Comisión del Mercado de las Telecomunicaciones) publishes data on each network's average price.

${ }^{13}$ In the case of asymmetric networks, we need to consider non-reciprocal rules such that the coefficients depend on the firms' identities.
} 


\subsection{Ramsey benchmark}

For future reference, we derive the social optimum in the ideal case in which the regulator knows all the relevant information and can dictate the prices under the constraint that the industry breaks even. Under linear pricing, consumer variable welfare is

$$
W(\mathbf{p})=\sum_{i=1}^{n} \alpha_{i}(\mathbf{p}) v\left(p_{i}\right)-T\left[\alpha_{1}(\mathbf{p}), \ldots, \alpha_{n}(\mathbf{p})\right]
$$

where $T\left(\alpha_{1}, \ldots, \alpha_{n}\right)$ denotes the average consumer's utility from not being able to consume her preferred service. We assume that $T(\boldsymbol{\alpha})$ is minimized at equal market share $\alpha_{i}=\frac{1}{n}$. The industry budget constraint is

$$
\sum_{i=1}^{n} \alpha_{i}(\mathbf{p}) R\left(p_{i}\right)=f
$$

Maximizing (2) subject to (3) yields a symmetric solution, $p_{i}=p^{R}$ for all $i=1, \ldots, n$, where the Ramsey price $p^{R}$ is the lowest price that satisfies the budget constraint:

$$
R\left(p^{R}\right)=f
$$

Since we assume $R^{m}>f$, we have $p^{R}<p^{m}$. Let $q\left(p^{R}\right) \equiv q^{R}$.

Clearly, in the case of competition in two-part tariffs, it is socially optimal to set a twopart tariff with variable price $c$ and fixed fee $F \geq f . T(\boldsymbol{\alpha})$ is minimized at equal market share $\alpha_{i}=\frac{1}{n}$.

\subsection{Timing}

The timing of the game we consider is the following:

1. The regulator chooses a linear access pricing rule in $\Lambda_{n}^{L}$.

2. All networks simultaneously choose retail prices.

3. Consumers make subscription and consumption decisions.

\section{Linear Pricing}

In this section, we consider competition in linear prices. We introduce two more properties. Property 4 is about the degree of substitutability among the networks. Because of our 
assumptions on $R(p)$, there exists a $\bar{p}>p^{m}$ such that $R(\bar{p})=f$. We assume in this section:

Property 4 (substitutability): $\alpha_{i}(p)=0$ if $p_{i} \geq \bar{p}$ and $p_{j}=p^{m}$ for some $j \neq i$.

The property says that a firm charging a high price yielding negative revenue per customer will have no market share if there is at least one competitor charging no more than the monopoly price. Hence the property guarantees that there is at least some mild level of substitutability. The assumption will be used to exclude the possibility of an equilibrium in which some firm charges such a high price. The only reason such a firm could survive is because of the revenue from access prices charged to its competitors. However, such a situation seems unstable in practice as the competitors could drive this firm out of business by lowering their prices.

Property 5 is a technical assumption to eliminate asymmetric equilibria for $n \geq 3$ :

Property 5 (proportional market share increases): Let $i, j$ and $k$ be three different firms and consider price vectors $\mathbf{p}$ and $\hat{\mathbf{p}}$ with $p_{k}<\hat{p}_{k}$ and $p_{m}=\hat{p}_{m}$ for all $m \neq k$. If $\alpha_{j}(\mathbf{p})>0$, then $\alpha_{i}(\hat{\mathbf{p}}) / \alpha_{j}(\hat{\mathbf{p}})=\alpha_{i}(\mathbf{p}) / \alpha_{j}(\mathbf{p})$.

Property 5 says that the ratio of market shares of any two firms is not affected by a price increase by a third firm. It is automatically satisfied when $n=2$ and is introduced to exclude asymmetric equilibria when $n \geq 3$. Together with the full coverage property this property means that all clients lost by the third firm will go to the competitors and each competitor's market share will increase by the same percentage.

\subsection{The main result}

We can now state the main result for the case of competition in linear prices.

Proposition 1 For any demand structure satisfying Properties 1-5 and for $n \geq 2$, there is a unique linear access pricing rule in $\Lambda_{n}^{L}$ defined by $a_{i j}-c_{0}=\frac{n}{n-1}\left(p_{i}-c\right)$ that implements, independently of the underlying demand conditions, the Ramsey outcome $\left(p_{i}=p^{R}\right.$ for all $i=1, \ldots, n)$ as the unique equilibrium, which is symmetric.

Note first the remarkable result that the optimal rule implementing the Ramsey outcome does not depend on the demand structure as long as it satisfies Properties 1-5. In what follows, we prove that the Ramsey outcome is the unique symmetric equilibrium and provide the intuition. The proof that no asymmetric equilibrium exists is provided in the Appendix. In section 3.2 we compare different access pricing rules in an intuitive way and provide a 
numerical example. In section 3.3, we discuss the robustness of our rule when we relax the full coverage assumption (property 3).

\subsubsection{Uniqueness of the candidate rule to achieve the Ramsey outcome}

Given a linear access pricing rule belonging to $\Lambda_{n}^{L}$ and under the assumption of balanced calling patterns ${ }^{14}$, the profit of network $i$ is given by:

$$
\Pi_{i}\left(p_{i}: \mathbf{p}_{-i}\right)=\alpha_{i}\left\{\left(p_{i}-c\right) q\left(p_{i}\right)-f\right\}+\sum_{j \neq i} \alpha_{i} \alpha_{j}\left\{h\left(p_{j}, p_{i}, c\right) q\left(p_{j}\right)-h\left(p_{i}, p_{j}, c\right) q\left(p_{i}\right)\right\}
$$

where the first term represents the retail profit and the second term represents the net access revenue (or deficit).

We show that among all the access pricing rules belonging to $\Lambda_{n}^{L}$, there is a unique candidate rule that satisfies a necessary condition to implement the Ramsey outcome $\left(p_{i}=\right.$ $p^{R}$ for $\left.i=1, \ldots, n\right)$. From (4), the first-order derivative of $\Pi_{i}$ with respect to $p_{i}$ is given by:

$$
\begin{aligned}
\frac{\partial \Pi_{i}}{\partial p_{i}}= & \frac{\partial \alpha_{i}}{\partial p_{i}}\left\{\left(p_{i}-c\right) q\left(p_{i}\right)-f\right\}+\alpha_{i}\left\{q\left(p_{i}\right)+\left(p_{i}-c\right) \frac{d q\left(p_{i}\right)}{d p_{i}}\right\} \\
& +\sum_{j \neq i}\left[\frac{\partial \alpha_{i}}{\partial p_{i}} \alpha_{j}+\frac{\partial \alpha_{j}}{\partial p_{i}} \alpha_{i}\right]\left\{h\left(p_{j}, p_{i}, c\right) q\left(p_{j}\right)-h\left(p_{i}, p_{j}, c\right) q\left(p_{i}\right)\right\} \\
& +\alpha_{i} \sum_{j \neq i} \alpha_{j}\left\{h_{2} q\left(p_{j}\right)-h_{1} q\left(p_{i}\right)-h\left(p_{i}, p_{j}, c\right) \frac{d q\left(p_{i}\right)}{d p_{i}}\right\} .
\end{aligned}
$$

As $\Pi_{i}$ is a differentiable function of $p_{i}$, a necessary condition to implement the Ramsey outcome is that the first-order derivative is zero at $p_{i}=p^{R}$ when all the other networks charge $p_{j}=p^{R}$ for $j \neq i$. We have $R\left(p^{R}\right)=f$ and $h\left(p_{j}, p_{i}, c\right) q\left(p_{j}\right)=h\left(p_{i}, p_{j}, c\right) q\left(p_{i}\right)$ at the symmetric equilibrium candidate with the Ramsey price, implying that the first and the third terms are zero in the above first-order derivative. Since $q\left(p_{i}\right)=q^{R}$ and $\alpha_{i}=\frac{1}{n}$ for $i=1, \ldots, n$ at the symmetric equilibrium candidate, the necessary condition holds only if the following conditions are satisfied by $h\left(p_{i}, p_{j}, c\right)$ :

$$
\begin{aligned}
1+\frac{n-1}{n}\left(h_{2}-h_{1}\right) & =0 \\
p^{R}-c-\frac{n-1}{n}\left[\left(h_{1}+h_{2}\right) p^{R}+h_{3} c+h_{4}\right] & =0 .
\end{aligned}
$$

\footnotetext{
${ }^{14}$ The assumption is from LRT $(1998 \mathrm{a}, \mathrm{b})$ and standard in the literature. It means that a consumer has an equal chance of calling a given consumer belonging to his network and another given consumer belonging to any other rival network.
} 
Given the regulator's informational constraint introduced in section 2.2, we find from the two conditions that $h_{1}=\frac{n}{n-1}, h_{2}=0, h_{3} c+h_{4}=-\frac{n}{n-1} c$. Therefore, we obtain the unique candidate in the set of linear access pricing rules as follows:

$$
a_{i j}-c_{0}=\frac{n}{n-1}\left(p_{i}-c\right)
$$

\subsubsection{Existence of a symmetric equilibrium}

We now show that under the access pricing rule $a_{i j}-c_{0}=\frac{n}{n-1}\left(p_{i}-c\right)$, the symmetric equilibrium with $p_{i}=p^{R}$ for $i=1, \ldots, n$ always exists. Given the access pricing rule (6), network $i$ 's profit is given by:

$$
\Pi_{i}\left(p_{i}: \mathbf{p}_{-i}\right)=\alpha_{i}\left[R\left(p_{i}\right)-f\right]+\frac{n}{n-1} \alpha_{i} \sum_{j \neq i} \alpha_{j}\left[R\left(p_{j}\right)-R\left(p_{i}\right)\right]
$$

Suppose that all the other networks except network 1 charge $p^{R}$. Then, because of the symmetry and the full coverage, we have $\alpha_{2}=\ldots=\alpha_{n}=\frac{1-\alpha_{1}}{n-1}$ and network 1's profit is given by;

$$
\begin{aligned}
\Pi_{1}\left(p_{1}: p^{R}, \ldots, p^{R}\right) & =\alpha_{1}\left[R\left(p_{1}\right)-f\right]+\frac{n}{n-1} \alpha_{1}\left(1-\alpha_{1}\right)\left[f-R\left(p_{i}\right)\right] \\
& =\frac{n \alpha_{1}}{n-1}\left(\alpha_{1}-\frac{1}{n}\right)\left[R\left(p_{1}\right)-f\right]
\end{aligned}
$$

Note first that $\Pi_{1}=0$ when $p_{1}=p^{R}$ and $\Pi_{1}=0$ for $p_{1} \geq \bar{p}$ under Property 4 . Consider any $p_{1}$ with $p_{1}<p^{R}$. Then, we have $\alpha_{1}>\frac{1}{n}$ and $R\left(p_{1}\right)<f$, implying $\Pi_{1}<0$. Consider now $p_{1} \in\left(p^{R}, \bar{p}\right)$. Then, we have $\alpha_{1}<\frac{1}{n}$ and $R\left(p_{1}\right)>f$, implying $\Pi_{1}<0$ if $\alpha_{1}>0$. Therefore, the symmetric equilibrium always exists.

To give the intuition, we consider the case of $n=2$ and examine network 1's price choice given $p_{2}=p^{R}$. Consider first $p_{1} \in\left(p^{R}, \bar{p}\right)$. In this case, network 1's retail profit per customer is $R\left(p_{1}\right)-f>0$. Its access revenue per customer is $2\left(1-\alpha_{1}\right) R\left(p_{2}\right)=2\left(1-\alpha_{1}\right) f$ while its access payment per customer is $2\left(1-\alpha_{1}\right) R\left(p_{1}\right)$, implying that it has a net access deficit per customer equal to $2\left(1-\alpha_{1}\right)\left[f-R\left(p_{1}\right)\right]$. Since $\alpha_{1}<\frac{1}{2}$ for $p_{1} \in\left(p^{R}, \bar{p}\right)$, the access deficit is larger than the retail profit and therefore the firm makes a loss. In contrast, in the case of $p_{1}<p^{R}$, the firm has a retail deficit per customer equal to $R\left(p_{1}\right)-f<0$ while it has a net access profit per customer equal to $2\left(1-\alpha_{1}\right)\left[f-R\left(p_{1}\right)\right]$. Since $\alpha_{1}>\frac{1}{2}$, the access profit is not large enough to cover the retail deficit and the firm's profit is still negative. In other words, the coefficient in the optimal linear access pricing rule $(2$ when $n=2)$ is such that (i) 
when $p_{1}=p^{R}$, network 1's profit is zero, (ii) when $p_{1} \in\left(p^{R}, \bar{p}\right)$, its retail profit per customer is smaller than its net access deficit per customer, implying that it makes a loss (iii) when $p_{1}<p^{R}$, its retail deficit per customer is larger than its net access revenue per customer, still implying that it makes a loss.

Note that in LRT (1998a), the non-existence of equilibrium occurs since a network can have an incentive to corner the market by deviating to a price lower than the price in the equilibrium candidate. In our equilibrium achieving the Ramsey outcome, the cornering strategy is not profitable since it requires the deviating network to charge a price lower than $p^{R}$, implying that the firm makes a loss after cornering the market.

\subsubsection{Non-existence of other symmetric equilibria}

We now show that under the access pricing rule $a_{i j}-c_{0}=\frac{n}{n-1}\left(p_{i}-c\right)$, no other symmetric equilibrium exists except $p_{i}=p^{R}$ for $i=1, \ldots, n$. Let $p$ be a symmetric equilibrium candidate. First, it is obvious that neither $p<p^{R}$ nor $p>\bar{p}$ can be an equilibrium since then each firm makes a negative profit. Therefore, we consider only $p \in\left(p^{R}, \bar{p}\right]$. Consider first $p=\bar{p}$. Then, each firm gets zero profit. Suppose now that network 1 deviates to $p_{1}=p^{m}$ while all the other networks continue to charge $\bar{p}$. Then, network 1's profit is given by:

$$
\Pi_{1}\left(p^{m} ; \bar{p}, \ldots, \bar{p}\right)=\frac{n \alpha_{1}}{n-1}\left(\alpha_{1}-\frac{1}{n}\right)\left[R^{m}-f\right]>0,
$$

where $\alpha_{1}=\alpha_{1}\left(p^{m} ; \bar{p}, \ldots, \bar{p}\right)>\frac{1}{n}$. Therefore, no symmetric equilibrium with $p=\bar{p}$ exists.

Let us consider now $p \in\left(p^{R}, \bar{p}\right)$. Then, from $(7)$, the first-order derivative of $\Pi_{i}$ with respect to $p_{i}$ is given by:

$$
\begin{aligned}
\frac{\partial \Pi_{i}\left(p_{i}: \mathbf{p}_{-i}\right)}{\partial p_{i}}= & {\left[R\left(p_{i}\right)-f\right] \frac{\partial \alpha_{i}}{\partial p_{i}}+\alpha_{i} \frac{d R\left(p_{i}\right)}{d p_{i}}-\frac{n}{n-1} \alpha_{i} \sum_{j \neq i} \alpha_{j} \frac{d R\left(p_{i}\right)}{d p_{i}} } \\
& +\frac{n}{n-1} \sum_{j \neq i}\left[\alpha_{j} \frac{\partial \alpha_{i}}{\partial p_{i}}+\alpha_{i} \frac{\partial \alpha_{j}}{\partial p_{i}}\right]\left[R\left(p_{j}\right)-R\left(p_{i}\right)\right] .
\end{aligned}
$$

At $p_{i}=p$ for $i=1, \ldots, n$, since $\sum_{j \neq i} \alpha_{j}=\frac{n-1}{n}$, the first-order derivative is given by:

$$
\frac{\partial \prod_{i}(p: p, \ldots, p)}{\partial p_{i}}=[R(p)-f] \frac{\partial \alpha_{i}}{\partial p_{i}}<0 \text { for } p \in\left(p^{R}, \bar{p}\right)
$$

Therefore, each firm has an incentive to undercut and no other symmetric equilibrium exists.

The access price rule $a_{i j}-c_{0}=\frac{n}{n-1}\left(p_{i}-c\right)$ intensifies retail price competition since by 
reducing $p_{i}$ network $i$ can reduce the access price that it should pay to the rival networks. In particular, at any symmetric price $p$ that allows networks to realize a positive retail profit (i.e., $R(p)>f$ ), each network has an incentive to choose a price lower than $p$. From (8), when network $i$ reduces its retail price, there are three effects on its profit. First, given its retail price, its retail profit increases through its expansion of market share. Second, given each network's market share, both its retail revenue per consumer and its access payment per consumer decrease. Third, given each network's retail price, the changes in the market shares affect its net access payment. In any symmetric equilibrium candidate with $p_{i}=p \in\left(p^{R}, \bar{p}\right)$ for $i=1, \ldots, n$, the second and the third effects are zero and the first is positive. Therefore, each firm has an incentive to deviate in order to increase its market share.

\subsection{Comparison with other rules when $n=2$}

Suppose that the regulator should choose an access pricing rule without knowing the demand structure while she only knows the marginal cost structure $\left(c, c_{0}\right)$. Consider duopolistic competition $^{15}$ and, for simplicity, let $a_{i}$ denote the access charge that network $i$ pays to the rival network. Then, from Proposition 1, we have the following corollary.

Corollary 1 Consider duopoly networks. Under Properties 1-4, the social welfare is strictly higher under the access pricing rule $a_{i}-c_{0}=2\left(p_{i}-c\right)$ than under any other fixed access price (including $\left.a_{i}=c_{0}\right)$, under the $\operatorname{ECPR}\left(a_{i}-c_{0}=p_{j}-c\right.$, for $\left.i \neq j\right)$ and under the GECPR $\left(a_{i}-c_{0}=p_{i}-c\right)$.

In order to give the intuition, we examine the first order derivative of network $i$ 's profit in each access pricing rule assuming that a symmetric equilibrium with $p_{1}=p_{2}=p<p^{m}$ exists under each rule.

First, under a fixed and reciprocal access price rule $a_{1}=a_{2}=a$, network $i$ 's profit is given by:

$$
\Pi_{i}\left(p_{i} ; p_{j}\right)=\alpha_{i}\left[R\left(p_{i}\right)-f\right]+\alpha_{i}\left(1-\alpha_{i}\right)\left(a-c_{0}\right)\left[q\left(p_{j}\right)-q\left(p_{i}\right)\right] .
$$

Therefore, the first-order derivative with respect to $p_{i}$ at $p_{i}=p_{j}=p$ is given by:

$$
[R(p)-f] \frac{d \alpha_{i}}{d p_{i}}+\frac{1}{2} \frac{d R_{i}}{d p_{i}}-\frac{\left(a-c_{0}\right)}{4} \frac{d q\left(p_{i}\right)}{d p_{i}}
$$

Consider first the case of the marginal cost pricing $\left(a=c_{0}\right)$. In this case, for any market share, each network has zero net access profit. Since $\frac{d \alpha_{i}}{d p_{i}}<0<\frac{d R_{i}}{d p_{i}}$, the first order condition

\footnotetext{
${ }^{15}$ The intuition obtained in this section applies to the case of $n>2$ as well.
} 
holds only for $p>p^{R}$ such that $R(p)>f$. Hence, the marginal cost pricing cannot achieve the Ramsey outcome. From (10), it is clear that as the access price becomes larger than the termination cost, network $i$ has an extra incentive to raise $p_{i}$ since by reducing the demand of its own customers, it can reduce its access payment. Since an increase in the reciprocal access price results in an increase in the retail price, LRT (1998a) find that networks can achieve the monopoly outcome if they can choose access price through private negotiation. In contrast, as the access price becomes smaller than the termination cost, network $i$ has an extra incentive to reduce $p_{i}$ in order to increase its access revenue. This is why LRT (1998a) find that the Ramsey access charge requires an access charge lower than the termination cost. More precisely, they find that Ramsey access charge, denoted by $a^{R}$, is given by:

$$
\frac{a^{R}-c_{0}}{2}=-\left(1-\frac{1}{\eta}\right)\left(p^{m}-p^{R}\right)
$$

where $\eta$ is the elasticity of demand and is assumed to be constant and larger than 1 . Note that in order to be able to compute the Ramsey access price, the regulator should have precise knowledge about the demand structure and the fixed cost $(f)$ such that she should be able to compute $\eta, p^{m}$ and $p^{R}$. Furthermore, LRT (1998a) show that the equilibrium does not exist for $a \neq c_{0}$ if the degree of substitutability of the two networks is high enough.

Second, in the case of the ECPR, network $i$ 's profit is given by:

$$
\Pi_{i}\left(p_{i} ; p_{j}\right)=\alpha_{i}\left[R\left(p_{i}\right)-f\right]+\alpha_{i}\left(1-\alpha_{i}\right)\left[q\left(p_{j}\right)\left(p_{i}-c\right)-q\left(p_{i}\right)\left(p_{j}-c\right)\right] .
$$

Therefore, the first-order derivative with respect to $p_{i}$ at $p_{i}=p_{j}=p$ is given by:

$$
[R(p)-f] \frac{d \alpha_{i}}{d p_{i}}+\frac{1}{2} \frac{d R_{i}}{d p_{i}}+\frac{1}{4}\left[q(p)-(p-c) \frac{d q\left(p_{i}\right)}{d p_{i}}\right]
$$

The first two terms in (11) are what we found in the first-order derivative under $a=c_{0}$ and have to do with the retail profit. The last term in (11) has to do with the access revenue and since $p>c$ and $\frac{d q\left(p_{i}\right)}{d p_{i}}<0$, it induces network $i$ to increase its retail price. Since under the ECPR a network can increase its access revenue by increasing its retail price, the ECPR induces each network to choose a price higher than the one under $a=c_{0}$.

Last, consider the following rule $a_{i}-c_{0}=\kappa\left(p_{i}-c\right)$ where $\kappa(\geq 0)$ is a constant. For instance, if $\kappa=1$, we have the GECPR and if $\kappa=0$, we have the marginal cost access 
pricing. Then, network $i$ 's profit is given by:

$$
\Pi_{i}\left(p_{i}: p_{j}\right)=\alpha_{i}\left[R\left(p_{i}\right)-f\right]+\kappa \alpha_{i}\left(1-\alpha_{i}\right)\left[R\left(p_{j}\right)-R\left(p_{i}\right)\right] .
$$

Therefore, the first-order derivative with respect to $p_{i}$ at $p_{i}=p_{j}=p$ is given by:

$$
[R(p)-f] \frac{d \alpha_{i}}{d p_{i}}+\frac{1}{2} \frac{d R_{i}}{d p_{i}}-\frac{\kappa}{4} \frac{d R_{i}}{d p_{i}}
$$

The first two terms in (12) are what we found in the first-order derivative under $a=c_{0}$ and have to do with the retail profit. The last term in (12) has to do with the access revenue and, since $\frac{d R_{i}}{d p_{i}}>0$, an increase in $\kappa$ induces network $i$ to reduce its retail price. This implies that the retail price under the marginal cost pricing is higher than the retail price under the GECPR, which is higher than the retail price under when $\kappa=2$ (i.e., the Ramsey price). Note that from (12), when $\kappa=2$, the only price satisfying the first-order condition is the Ramsey price.

Table 1 summarizes the quantitative effects of the different access pricing rules for a numerical example employing the duopoly Hotelling model with consumers having demand function with constant elasticity. For this table we used the following parameters: $\eta=1.5$, $c_{0}=0.05, c=0.12, f=0, \sigma=0.001$ and utility function $u(q)=300 q^{1 / 3}$. In this case monopoly price would equal $p^{m}=0.36$. Consumer surplus (CS) is defined as the indirect utility $v\left(p^{*}\right)$. Note that no equilibrium exists in this case of the ECPR rule.

\begin{tabular}{l|c|c|c|c|}
\cline { 2 - 5 } Bill and Keep & retail price & profit/firm & CS & TS \\
\cline { 2 - 5 } Cost-based & 0.21 & 46.36 & 438.64 & 485.00 \\
\cline { 2 - 5 } ECPR & 0.25 & 52.32 & 397.01 & 449.33 \\
\cline { 2 - 5 } GECPR & na & na & na & na \\
\cline { 2 - 5 } Ramsey & 0.21 & 46.19 & 439.58 & 485.77 \\
\cline { 2 - 5 } & 0.12 & 0.00 & 577.35 & 577.35 \\
\cline { 2 - 5 }
\end{tabular}

Table 1: Numerical results for different access pricing rules with constant elasticity demand.

Table 2 summarizes the quantitative effects of the different access pricing rules for a numerical example employing the duopoly Hotelling model with consumers having linear demand. For this table we used the following parameters (also employed by Carter and Wright (1999)): $c_{0}=0, c=1, f=0, \sigma=0.01$ and demand function $q(p)=10-p$. In this case monopoly price would equal $p^{m}=5.5$. Again, consumer surplus (CS) is defined as the indirect utility $v\left(p^{*}\right)$. Note that Bill and Keep and cost-based regulation yield the same results since $a=c_{0}=0$. 


\begin{tabular}{l|c|c|c|c|}
\cline { 2 - 5 } Bill and Keep & retail price & profit/firm & CS & TS \\
\cline { 2 - 5 } Cost-based & 4.44 & 9.56 & 15.48 & 25.03 \\
\cline { 2 - 5 } ECPR & 4.44 & 9.56 & 15.48 & 25.03 \\
\cline { 2 - 5 } GECPR & 5.35 & 10.11 & 10.83 & 20.94 \\
\cline { 2 - 5 } Ramsey & 3.41 & 7.94 & 21.73 & 29.67 \\
\cline { 2 - 5 } & 1.00 & 0.00 & 40.50 & 40.50 \\
\cline { 2 - 5 }
\end{tabular}

Table 2: Numerical results for different access pricing rules with linear demand.

\subsection{Robustness: relaxing full coverage}

In this part, we discuss the robustness of our results to relaxing the full coverage assumption (property 3). Hence, we here assume that $\sum_{i=1}^{n} \alpha_{i}(p: p, \ldots, p)$ strictly decreases with $p$. We continue to normalize the mass of potential consumers at one. Since $\sum_{i=1}^{n} \alpha_{i}(p: p, \ldots, p)$ represents the total mass of consumers who subscribe to one of the networks, it cannot be larger than one. In this setting, the Ramsey price is still characterized by $R\left(p^{R}\right)=f$. Let $\alpha_{i}\left(p^{R}: p^{R}, \ldots, p^{R}\right)=\alpha^{R}>0$. Then, we have the following result:

Proposition 2 Suppose that $\sum_{i=1}^{n} \alpha_{i}(p: p, \ldots, p)$ strictly decreases with $p$. For any demand structure satisfying Properties 1, 2, 4,

(i) there is a unique linear access pricing rule in $\Lambda_{n}^{L}$ defined by $a_{i j}-c_{0}=\frac{1}{\alpha^{R}(n-1)}\left(p_{i}-c\right)$ that satisfies a necessary condition to achieve the Ramsey outcome $\left(p_{i}=p^{R}\right.$ for $\left.i=1, \ldots, n\right)$ as an equilibrium

(ii) under the rule, $p_{i}=p^{R}$ for $i=1, \ldots, n$ is an equilibrium.

Note that the access pricing rule in Proposition 2 generalizes the one in Proposition 1 since under the full coverage, $\alpha^{R}=\frac{1}{n}$.

Proof. (i) The first-order derivative of $\Pi_{i}$ with respect to $p_{i}$ is given by (5). A necessary condition to implement the Ramsey outcome is that the first-order derivative is zero at $p_{i}=p^{R}$ for $i=1, \ldots, n$. Since $R\left(p^{R}\right)=f$ and $h\left(p_{j}, p_{i}, c\right) q\left(p_{j}\right)=h\left(p_{i}, p_{j}, c\right) q\left(p_{i}\right)$ at the symmetric equilibrium candidate, the first and the third terms are zero in (5) at $p_{i}=p^{R}$ for $i=1, \ldots, n$. Since $q\left(p_{i}\right)=q^{R}$ and $\alpha_{i}=\alpha^{R}$ for $i=1, \ldots, n$ at the symmetric equilibrium candidate, the necessary condition holds only if the following conditions are satisfied by $h\left(p_{i}, p_{j}, c\right)$ :

$$
\begin{aligned}
1+(n-1) \alpha^{R}\left(h_{2}-h_{1}\right) & =0 \\
p^{R}-c-(n-1) \alpha^{R}\left[\left(h_{1}+h_{2}\right) p^{R}+h_{3} c+h_{4}\right] & =0 .
\end{aligned}
$$


From the two conditions, we find that $h_{1}=\frac{1}{\alpha^{R}(n-1)}, h_{2}=0, h_{3} c+h_{4}=-\frac{c}{\alpha^{R}(n-1)}$. Therefore, we obtain the unique candidate in the set of linear access pricing rules as follows:

$$
a_{i j}-c_{0}=\frac{1}{\alpha^{R}(n-1)}\left(p_{i}-c\right)
$$

(ii) Given the access pricing rule, network $i$ 's profit is given by:

$$
\Pi_{i}\left(p_{i}: p_{j}\right)=\alpha_{i}\left[R\left(p_{i}\right)-f\right]+\frac{1}{\alpha^{R}(n-1)} \alpha_{i} \sum_{j \neq i} \alpha_{j}\left[R\left(p_{j}\right)-R\left(p_{i}\right)\right]
$$

Suppose that all the other networks except network 1 charge $p^{R}$. Then, because of the symmetry, we have $\alpha_{2}=\ldots=\alpha_{n}$ and network 1's profit is given by;

$$
\begin{aligned}
\Pi_{1}\left(p_{1} ; p^{R}, \ldots, p^{R}\right) & =\alpha_{1}\left[R\left(p_{1}\right)-f\right]+\frac{1}{\alpha^{R}} \alpha_{1} \alpha_{2}\left[f-R\left(p_{1}\right)\right] \\
& =\alpha_{1} \frac{\left[\alpha^{R}-\alpha_{2}\right]}{\alpha^{R}}\left[R\left(p_{1}\right)-f\right]
\end{aligned}
$$

where $\alpha_{2}=\alpha_{2}\left(p^{R} ; p_{1}, p^{R}, \ldots, p^{R}\right)$. Note first that $\Pi_{1}=0$ when $p_{1}=p^{R}$ and $\Pi_{1}=0$ for $p_{1} \geq \bar{p}$ under Property 4. Consider any $p_{1}$ with $p_{1}<p^{R}$. Then, from the monotonicity, we have $\alpha^{R}>\alpha_{2}$ and $R\left(p_{1}\right)<f$, implying $\Pi_{1}<0$. Consider now $p_{1} \in\left(p^{R}, \bar{p}\right)$. Then, we have $\alpha^{R}<\alpha_{2}$ and $R\left(p_{1}\right)>f$, implying $\Pi_{1}<0$ if $\alpha_{1}>0$.

Remark 1: Even though we relax the full coverage assumption, the rule presented in Proposition 1 implements the Ramsey outcome if the market is mature in that the total mass of consumers choosing to join one among the networks is equal to one at the Ramsey price. Otherwise, the regulator needs to know $\alpha^{R}$ and in this sense the optimal access pricing rule is informationally demanding. However, even when it is difficult for the regulator to know $\alpha^{R}$, this does not imply that she should adopt one of the alternative access pricing rules presented in Section 2.2. As the comparison of different rules in Section 3.2 has shown, the intuition that one can intensify the retail competition by making the access price that network $i$ pays to other networks increase with its retail price holds generally. More precisely, since $\alpha^{R} \leq 1 / n$ holds, we have $\frac{1}{\alpha^{R}(n-1)} \geq n /(n-1)$. Therefore, one can use the access pricing rule presented in Proposition 1, $a_{i j}-c_{0}=\frac{n}{n-1}\left(p_{i}-c\right)$ : although the equilibrium price under the rule is higher than the Ramsey price, it is lower than the equilibrium price under any fixed access price (larger than the termination cost), or under the ECPR or under the GECPR. Furthermore, the previous rule is not informationally demanding. 


\section{Two-part tariffs}

Although linear prices are used in practice, especially for pre-paid cards in the mobile telecommunication market, non-linear prices are also heavily used. Moreover, the literature has embraced two-part tariff competition as the standard. In this section we study competition in two-part tariffs when our rule is adapted to make access charges depend (linearly) on average retail prices. After showing in section 4.1 that the class of rules we consider induces networks to choose the marginal cost pricing in a general setting, we investigate in section 4.2 other properties of our rules in a duopoly model à la LRT (1998a).

It is clear that firms would prefer to use two-part tariffs rather than linear prices. Namely, when firms are allowed to use a two-part tariff, they will in general find it optimal to set a strictly positive fixed fee to extract consumer surplus. If one would naively use the access pricing rule that is optimal in the case of linear prices (i.e., $a_{i j}=c_{0}+2\left(p_{i}-c\right)$ ) when firm $i$ uses tariff $T_{i}=F_{i}+p_{i} q$, no symmetric equilibrium would exist. ${ }^{16}$ Therefore, the rule needs to be adapted to give sensible and satisfactory results. Inspired by the previous discussion, we propose to make the access charge paid by firm $i$ depend linearly on its average retail price as follows:

$$
a_{i}=c_{0}+\kappa\left(\frac{F_{i}+p_{i} q\left(p_{i}\right)}{q\left(p_{i}\right)}-c\right),
$$

where $a_{i}$ represents the access charge that firm $i$ pays to each rival firm. Since it only depends on firm $i$ 's retail prices, we use $a_{i}$ instead of $a_{i j}$ for simplicity.

\subsection{A main result: marginal cost pricing}

Under the standard full coverage assumption, we find, as a main result, that firms always will set variable price equal to marginal $\operatorname{cost} c$, independently of $\kappa$ and their market shares, for all $\kappa \leq 1$. In what follows, we first explain intuitively why the class of access pricing rules we consider generates the marginal cost pricing.

Given $\left(p_{i}, F_{i}\right)$, the net surplus of a consumer of network $i$ is given by:

$$
w_{i}=v\left(p_{i}\right)-F_{i} .
$$

\footnotetext{
${ }^{16}$ More precisely, firms would have incentives to reduce variable price below cost (for example, to zero if negative prices are not allowed) so that access charge becomes negative. Each network would then receive money from its rival for each off-net call made by its subscribers. This then leads the firms to compete for market share by reducing fixed fees resulting in huge losses.
} 
Let $\mathbf{w} \equiv\left(w_{1}, \ldots, w_{n}\right)$. The market share of network $i$ is given by $\alpha_{i}(\mathbf{w})$. For instance, in the Hotelling model of duopoly (LRT, 1998a,b), we have

$$
\alpha_{i}=\frac{1}{2}+\sigma\left(w_{i}-w_{j}\right)
$$

where $\sigma \equiv 1 /(2 t)$ and $t$ is the transportation cost in the Hotelling model. We first consider the case of $\kappa=0$ which corresponds to $a_{i}=c_{0}$. Then, network $i$ 's profit is given by:

$$
\Pi_{i}\left(p_{i}, F_{i}\right)=\alpha_{i}\left[\left(p_{i}-c\right) q\left(p_{i}\right)+F_{i}-f\right]=\alpha_{i} \pi_{i}-\alpha_{i} f .
$$

where $\pi_{i} \equiv\left(p_{i}-c\right) q\left(p_{i}\right)+F_{i}$ represents network $i$ 's retail profit per customer gross of the fixed cost $f$ when $\kappa=0$. It is useful to think that network $i$ chooses $\left(p_{i}, w_{i}\right)$ instead of $\left(p_{i}, F_{i}\right)$. Then, we have:

$$
\begin{aligned}
\Pi_{i}\left(p_{i}, w_{i}\right) & =\alpha_{i}\left[\left(p_{i}-c\right) q\left(p_{i}\right)+v\left(p_{i}\right)-w_{i}-f\right] \\
& =\alpha_{i}\left[u\left(q\left(p_{i}\right)\right)-c q\left(p_{i}\right)-w_{i}-f\right]
\end{aligned}
$$

Given $w_{i}$ (hence, given $\alpha_{i}$ ), maximizing $\Pi_{i}$ with respect to $p_{i}$ is equivalent to maximizing total surplus, which leads to the marginal cost pricing $\left(i . e ., p_{i}=c\right)$ for any $\alpha_{i}$ as LRT (1998a) show.

Consider now $\kappa \neq 0$. Then, we have the following expression for network $i$ 's profit:

$$
\Pi_{i}\left(p_{i}, F_{i}\right)=\alpha_{i}\left\{\left[\left(p_{i}-c-\left(1-\alpha_{i}\right)\left(a_{i}-c_{0}\right)\right] q\left(p_{i}\right)+F_{i}-f+\Sigma_{j \neq i} \alpha_{j}\left(a_{j}-c_{0}\right) q\left(p_{j}\right)\right\} .\right.
$$

In particular, from (13) the total access payment (net of the total termination cost) that network $i$ makes to network $j$ is given by:

$$
\alpha_{i}\left(1-\alpha_{i}\right)\left(a_{i}-c_{0}\right) q\left(p_{i}\right)=\alpha_{i}\left(1-\alpha_{i}\right) \kappa \pi_{i} .
$$

The above equation shows that network $i$ 's access payment (net of the termination cost) per customer is a fraction $\left(1-\alpha_{i}\right) \kappa$ of its retail profit per customer $\pi_{i}$. Inserting the above expression into the profit function leads to

$$
\Pi_{i}\left(p_{i}, F_{i}\right)=\alpha_{i}\left[\left(1-\kappa\left(1-\alpha_{i}\right)\right) \pi_{i}-f+\kappa \Sigma_{j \neq i} \alpha_{j} \pi_{j}\right]
$$


which is equivalent to

$$
\Pi_{i}\left(p_{i}, w_{i}\right)=\alpha_{i}\left[\left(1-\kappa\left(1-\alpha_{i}\right)\right)\left(R\left(p_{i}\right)+v\left(p_{i}\right)-w_{i}\right)\right]-\alpha_{i} f+\alpha_{i} \kappa \Sigma_{j \neq i} \alpha_{j} \pi_{j}
$$

Therefore, as long as $\left(1-\kappa\left(1-\alpha_{i}\right)\right) \geq 0$ (which is satisfied when $\kappa \leq 1$ ), the profit maximization with respect to $p_{i}$ for given $w_{i}$ leads to the marginal cost pricing $\left(i . e ., p_{i}=c\right.$ ) for any $\alpha_{i}$ and for any $\kappa \leq 1$. The intuition is clear from (15). Given $w_{i}$ (hence, given $\alpha_{i}$ ), when we maximize $\Pi_{i}$ with respect to $p_{i}$, only the first term matters in (15) and therefore maximizing $\Pi_{i}$ is equivalent to maximizing the profit per customer $\pi_{i}$ as is the case when $\kappa=0$. This is because, under our access pricing rule, network $i$ 's access payment (net of the termination cost) per customer is just a fraction of its retail profit per customer.

The above intuition suggests that our access pricing rule gives the marginal cost pricing under various circumstances; as long as $a_{i}=c_{0}$ generates the marginal cost pricing, our access pricing rule generates the marginal cost pricing as well. In fact, we show this later on when firms can invest to improve quality of their networks or when firms compete by providing a menu of two-part tariffs to heterogeneous customers or when firms are asymmetric in terms of customer brand loyalty.

The following proposition presents our main result:

Proposition 3 Assume Properties 1-3. (i) For any $n \geq 2$ and $\kappa \leq 1$, all networks choose the same variable price $p=c$.

(ii) More specifically, in the case of the Hotelling duopoly model (LRT, 1998a,b), when $\kappa \leq 1$ and for small enough $\sigma>0$, there exists a unique equilibrium, which is symmetric. In the equilibrium, networks charge variable price $p=c$ and fixed fee $F=f+(2-\kappa) /(4 \sigma)$. Equilibrium profits per firm equal $(2-\kappa) /(8 \sigma)$.

Hence, for any $\kappa \leq 1$ we obtain efficient pricing. By varying $\kappa$ we can address and achieve further objectives, without distorting the efficient marginal cost pricing result. Furthermore, proposition 3(ii) shows that the profit is not neutral and decreases with $\kappa$. Given a reduction in network $i$ 's fixed fee, an increase in $\kappa$ increases $i$ 's benefit from the resulting reduction in its access payment. Therefore, an increase in $\kappa$ intensifies competition in terms of the fixed fee and thereby decreases the profit. This implies that, by increasing $\kappa$, the regulator or competition authority can improve consumer welfare at the expense of firms' profits.

However, we cannot push firms' profits all the way to zero. Namely, this would require firms to set the competitive schedule $T=f+c q$, which in turn requires setting $\kappa=2$. But 
this cannot be an equilibrium since the average price at this equilibrium is strictly above $c$, so that access charge is above marginal cost. Then, a network could deviate by offering a schedule $\tilde{T}=\tilde{F}+\tilde{p} q$, where $0<\tilde{p}<c$ and $\tilde{F}=-(\tilde{p}-c) q(\tilde{p})$, such that its average price is exactly equal to marginal cost $c$ and such that its market share $\tilde{\alpha}_{i}$ is positive but less than one half. The deviating firm then pays an access fee equal to termination cost $c_{0}$ so that both on-net and off-net calls are at marginal cost $c$, which in turn equals average price. It thus would earn zero net profits from calls made by its own subscribers but would then make strictly positive profits because the net access revenue exceeds the incurred fixed costs: $2\left(1-\tilde{\alpha}_{i}\right) \tilde{\alpha}_{i} f>\tilde{\alpha}_{i} f$.

\subsection{Extensions}

In this subsection, we consider the Hotelling model à la LRT (1998a).

\subsubsection{Expanding coverage}

In this subsection we take the participation condition of consumers seriously. In the previous section, and in most of the related literature, one typically assumes that $\sigma$ is small enough, which implies that transportation cost $t$ is very large. This would lead consumers in the center of the Hotelling model to forego subscribing to a network. In order to maintain the full coverage assumption one needs to assume that consumers have a high enough valuation for being subscribed to the network, even if no one else subscribes or when hardly any calls are made (typically, $v_{0}$, introduced in section 2, is assumed to be large enough). A reason for this could be that then one can call 911 in emergencies. In this subsection, we relax this assumption and assume that $v_{0}$ is not large and smaller than $f$. Hence, the number of subscribers in equilibrium will depend on the net surplus consumers obtain, which in turn depends on the degree of competition between two networks.

Assume that consumers' valuation from subscribing to a network when in total $\rho$ consumers are subscribing to one of the networks is such that a consumer at distance $x$ from his network that charges $T=F+p q$, receives utility $v_{0}+\rho v(p)-F-x t$.

Let us denote

$$
\lambda=\frac{v_{0}+v(c)-f}{t} .
$$

When total coverage by two networks charging $T=f+c q$ equals $2 \alpha \leq 1$, social welfare equals

$$
W(\alpha)=2 \alpha\left(v_{0}+2 \alpha v(c)-f-t \alpha / 2\right)
$$


$W^{\prime}(\alpha)=2\left(\alpha(4 v(c)-t)+v_{0}-f\right)$ and $W^{\prime \prime}(\alpha)=2(4 v(c)-t)$. If $t \geq 4 v(c), W^{\prime}(\alpha)<0$ for all positive $\alpha$ and consumer welfare is maximized at $\alpha=0$. If $t<4 v(c), W(\alpha)$ is convex and maximized at zero or $1 / 2$. Since $W(0)=0$ and $W(1 / 2)=v_{0}+v(c)-f-t / 4$, we find that the full coverage is optimal when $\lambda>1 / 4$ and that no coverage is optimal when $\lambda \leq 1 / 4$. However, also note that when networks charge the very competitive schedule $T=f+c q$, the consumer in the middle only receives positive net surplus if $v_{0}+v(c)-f-t / 2>0$. Hence, implementing the consumer surplus maximizing network prices when $\lambda \in(1 / 4,1 / 2)$ is incompatible with voluntary participation. We will henceforth assume that $\lambda>1 / 2$ so that full coverage is both feasible and desirable.

We now consider the necessary condition for a full coverage equilibrium to exist. Recall from Proposition 3 that equilibrium prices are $T=f+t-\kappa t / 2+c q$. To have full coverage and voluntary participation in such an equilibrium, one needs the consumer in the center of the interval to be willing to subscribe when anticipating that everyone will subscribe to one of the networks. This condition reads $v_{0}+v(c)-t / 2-(f+t-\kappa t / 2)>0$, or equivalently,

$$
\lambda=\frac{v_{0}+v(c)-f}{t}>\frac{3-\kappa}{2} .
$$

In particular, for $\kappa=0$ there is no equilibrium in which the market is fully covered when $\left(v_{0}+v(c)-f\right) / t<3 / 2$. By increasing $\kappa$ one relaxes the full coverage constraint. In particular, as long as $\lambda \in(1,3 / 2)$, no full coverage equilibrium exists when subscription is voluntary and cost based access price regulation $(\kappa=0)$ is applied. However, when using our rule with $\kappa=1$, existence of the full coverage equilibrium is restored when consumers anticipate that the market will be covered. An increase in $\kappa$ intensifies competition between the networks and thereby makes them leave a larger surplus to consumers, which makes full coverage more likely. Summarizing, we have:

Proposition 4 In the Hotelling model of LRT (1998a), assume $v_{0}<f$. Then, an increase in $\kappa$ makes full coverage more likely. For $\lambda \in(1,2 / 3)$ where $\lambda \equiv\left[v_{0}+v(c)-f\right] / t$, no full coverage equilibrium exists under the cost based access price regulation (i.e., when $\kappa=0$ ) but existence of the full coverage equilibrium is restored when $\kappa=1$.

\subsubsection{Investment}

Valletti and Cambini (2005) analyze the effects of fixed access fees on firms' incentives to invest in the quality of their network. They find that even if access charge is fixed at marginal cost of termination, quality decisions are strategic substitutes, and firms underinvest in 
quality. Moreover, they show that the underinvestment is even more severe when access charges are raised (slightly) above the marginal cost of termination, since the network with the highest quality will have more calls going out to the other network than calls coming in from the other network and will therefore run an access revenue deficit. Since investments do not increase gross industry profits, Valletti and Cambini (2005) find that if firms can freely negotiate reciprocal access charges they will set it above marginal cost which would imply even lower investment levels and inefficiently high usage fees. To induce efficient investment levels one needs to set access charges below marginal cost of termination. In order to calculate this optimal access fee the regulator needs information about demand. Moreover, when access fee is set in this way, usage fee will be inefficiently low (below marginal cost). That is, to induce dynamic efficiency one is forced to lose static efficiency.

In this subsection we adopt Valletti and Cambini's (2005) framework of investment but access charges are defined by our retail benchmarking rule (13). We show that for any $\kappa \leq 1$ the rule induces firms to set usage fee equal to marginal cost. Moreover, by choosing $\kappa$ appropriately (below zero), one can induce socially efficient investment. In addition, setting the appropriate $\kappa$ does not require knowledge of the demand function. Finally, it is shown that firms may obtain higher net profits under this socially optimal rule than with any fixed access fee.

Following Valletti and Cambini (2005) we assume that firms in a first stage invest in quality $\rho_{i} \geq \bar{\rho}>0$, and that they afterwards compete in two-part tariffs $T_{i}=F_{i}+p_{i} q$. The cost of investment is given by the convex function $I\left(\rho_{i}\right)$. Each subscriber subscribes to exactly one of both networks and a subscriber to network $i$ makes $\rho_{i} q\left(p_{i}\right)$ calls and receives indirect utility $\rho_{i} v\left(p_{i}\right)$. We first find the socially optimal investment in a symmetric equilibrium $\rho_{i}=\rho_{j}=\rho$. Assume $p_{i}=p_{j}=c$, which is required by static efficiency. Then, the socially optimal $\rho$ is determined by maximizing $\rho v(c)-2 I(\rho)$, which gives $v(c)=2 I^{\prime}(\rho)$.

Now we turn to the competition between the two networks. Since we will need to know which two-part tariffs firms set when they are of different quality, we will not be able to restrict attention at the pricing stage to symmetric equilibria. Given $\rho_{1}$ and $\rho_{2}$, gross profit of network $i$ (not including investment costs) is given by

$\Pi_{i}(p, w)=\alpha_{i}\left[\left(1-\kappa\left(1-\alpha_{i}\right)\right)\left(\rho_{i} R\left(p_{i}\right)+\rho_{i} v\left(p_{i}\right)-w_{i}-f\right)+\kappa\left(1-\alpha_{i}\right)\left(\rho_{j} R\left(p_{j}\right)+\rho_{j} v\left(p_{j}\right)-w_{j}-f\right)\right]$.

Thus

$$
\frac{\partial \prod_{i}}{\partial p_{i}}=\alpha_{i}\left(1-\kappa\left(1-\alpha_{i}\right)\right) \rho_{i}\left(p_{i}-c\right) q^{\prime}\left(p_{i}\right)
$$


and we obtain again the marginal cost pricing result, independently of $\kappa, \rho_{i}$ and $\rho_{j}$ as long as $\kappa \leq 1$.

Fixed fees will turn out to depend on networks' qualities. Namely, given $p_{1}=p_{2}=c$, we have

$$
\begin{aligned}
\frac{\partial \prod_{i}}{\partial w_{i}}= & \sigma\left[\left(1-\kappa\left(1-\alpha_{i}\right)\right)\left(\rho_{i} v(c)-w_{i}-f\right)+\kappa\left(1-\alpha_{i}\right)\left(\rho_{j} v(c)-w_{j}-f\right)\right] \\
& +\alpha_{i}\left[-1+\kappa\left(1-\alpha_{i}\right)+\kappa \sigma\left[\left(\rho_{i}-\rho_{j}\right) v(c)-w_{i}+w_{j}\right]\right] .
\end{aligned}
$$

The first order conditions can be solved explicitly to yield

$$
w_{i}=\frac{-6+3 \kappa+4 \sigma v(c)\left(2 \rho_{i}+\rho_{j}\right)+4 \kappa(\sigma v(c))^{2}\left(\rho_{i}-\rho_{j}\right)^{2}}{12 \sigma}-f
$$

and

$$
\alpha_{i}=\frac{3+2 \sigma v(c)\left(\rho_{i}-\rho_{j}\right)}{6}
$$

Net profits in the second stage are then given by

$$
\Pi_{i}\left(\rho_{i}, \rho_{j}\right)=\frac{\left(3+2 \sigma v(c)\left(\rho_{i}-\rho_{j}\right)\right)^{2}\left(6-\kappa\left(3+2 \sigma v(c)\left(\rho_{i}-\rho_{j}\right)\right)\right)}{216 \sigma}-I\left(\rho_{i}\right) .
$$

Taking first order derivatives and looking for a symmetric equilibrium in qualities yields $\rho_{i}=\rho$ where the latter solves

$$
I^{\prime}(\rho)=v(c)(4-3 \kappa) / 12
$$

Since $I(\cdot)$ is convex and $v(c)$ is positive, it follows immediately that equilibrium investment is decreasing in $\kappa$. Letting $\kappa=0$ corresponds exactly to Valletti and Cambini's (2005) case of cost based access price regulation where firms invest at the inefficiently low level determined by $I^{\prime}(\rho)=v(c) / 3$. By setting $\kappa=-2 / 3$ one obtains $2 I^{\prime}(\rho)=v(c)$, which corresponds to the efficient level of investment. The negative factor $\kappa$ means that access charges are below marginal cost. The intuition for the result that $\kappa$ should be set below zero is similar to the one underlying the result of Valletti and Cambini (2005) that a fixed access price should optimally set below the termination cost, but is even clearer. Namely, in our case variable prices in the second stage are always equal to marginal cost. Since consumers at the higher quality network make more calls, the higher quality network will have more outgoing than incoming calls (independently of the market shares), so that when access charge is above 
marginal cost (that is, $\kappa>0$ ), it will suffer from an access revenue deficit. This reduces firms' incentives to invest in the quality of their network in comparison with the situation where access charge is equal to marginal cost $(\kappa=0)$. When access charge is below marginal cost (that is, $\kappa<0$ ), the effect is opposite and this increases firms' incentives to invest.

An important difference with respect to Valletti and Cambini (2005) is that here we can induce efficient investment without distorting efficient pricing, since for any $\kappa \leq 1$, variable usage prices will be set to true marginal cost, independently of the qualities of the networks. Under any fixed access charge $a \neq c_{0}$, variable usage price will be set equal to perceived marginal cost, which is not equal to true marginal cost, and is thus necessarily inefficient. Moreover, it makes the computation of equilibria in the investment stage very cumbersome. Indeed, Valletti and Cambini (2005)'s main results are about marginal deviations from cost based access charges.

Summarizing, we have:

Proposition 5 In the Hotelling model of LRT (1998a), suppose that networks invest in quality $\left(\rho_{1}, \rho_{2}\right)(\geq(\bar{\rho}, \bar{\rho}))$ after the access pricing rule is determined and before they engage in competition in two-part tariffs.

(i) For any $\left(\rho_{1}, \rho_{2}\right) \geq(\bar{\rho}, \bar{\rho})$ and for any $\kappa \leq 1$, each network chooses the variable price equal to the marginal cost.

(ii) When $\kappa=-2 / 3$, each network has a socially efficient incentive to invest. In other words, $\kappa=-2 / 3$ achieves both the static efficiency and the dynamic efficiency.

It is worthwhile to compare the profits of firms in the symmetric equilibrium under our optimal benchmarking rule with $\kappa=-2 / 3$ with those under cost based access charges $(\kappa=0)$. In the first case they are equal to $1 /(3 \sigma)-I\left(\rho^{*}\right)$ (where $\rho^{*}$ denotes the socially efficient level of investment determined by $\left.I^{\prime}\left(\rho^{*}\right)=v(c) / 2\right)$, while in the second case they are equal to $1 /(4 \sigma)-I(\rho)$ (where $\rho$ is determined by $I^{\prime}(\rho)=v(c) / 3$ ). Depending on the parameters, profits in the first case may be higher, despite the higher investments made. For example, when $I(\rho)=\rho^{2} / 2, v(p)=(10-p)^{2} / 2, \sigma=0.001, c_{0}=1$ and $c=2$, and a minimum level of investment is set at $\bar{\rho}=10$. In this case the socially efficient investment level equals $\rho^{*}=16$ and profit per firm equals 205.33. On the other hand, cost based access charges $(\kappa=0)$ would lead to an investment level $\rho=10.67$ and per firm profit of 193 .

Finally, in case of bilateral negotiations about the reciprocal access charge, firms may be able to agree on such high access charges that investment will be set at the minimum $\bar{\rho}=10$. In this case profits would be equal to 200. This illustrates that our socially optimal retail 
benchmarking approach may provide higher profits for firms than any bilaterally agreed upon fixed access charge.

\subsubsection{Heterogeneous consumers}

Consider now the case of heterogeneous consumers as in Dessein (2003) and Hahn (2004). There is a fraction $\mu>0$ of light consumers and a fraction $1-\mu>0$ of heavy consumers: let $\theta$ denote the type of a consumer with $\theta=H, L .{ }^{17}$ From consuming $q$, a $\theta$-type consumer obtains gross utility $u_{\theta}(q)$ in which

$$
u_{H}^{\prime}(q)>u_{L}^{\prime}(q)>0 \text { and } u_{\theta}^{\prime \prime}(q)<0 \text { for } \theta=H, L .
$$

Given a price $p$, let $q^{\theta}(p)$ denote the volume of calls chosen by a consumer of type $\theta$; we have $q^{H}(p)>q^{L}(p)$ for any $p>0$. Network $i$ offers a menu of two-part tariffs $\left\{F_{i}^{\theta}, p_{i}^{\theta}\right\}$ for $\theta=H, L$. For simplicity, $q_{i}^{H}=q^{H}\left(p_{i}^{H}\right)$ and $q_{i}^{L}=q^{L}\left(p_{i}^{L}\right)$. Let $v_{\theta}(p)$ be the indirect utility function of type $\theta$. We introduce the following notations:

$$
\begin{aligned}
w_{i}^{H} & \equiv v_{H}\left(p_{i}^{H}\right)-F_{i}^{H}, w_{i}^{L} \equiv v_{L}\left(p_{i}^{L}\right)-F_{i}^{L} ; \\
\alpha_{i}^{H} & =\frac{1}{2}+\sigma\left(w_{i}^{H}-w_{j}^{H}\right), \alpha_{i}^{L}=\frac{1}{2}+\sigma\left(w_{i}^{L}-w_{j}^{L}\right) .
\end{aligned}
$$

Let $\alpha_{i} \equiv \mu \alpha_{i}^{L}+(1-\mu) \alpha_{i}^{H}$ for $i=1,2$.

We consider again the access pricing rule in which the markup of the access price that network $i$ pays to the rival network is $\kappa$ times its average price mark up:

$$
a_{i}-c_{0}=\kappa\left(\frac{\mu \alpha_{i}^{L}\left[F_{i}^{L}+p_{i}^{L} q_{i}^{L}\right]+(1-\mu) \alpha_{i}^{H}\left[F_{i}^{H}+p_{i}^{H} q_{i}^{H}\right]}{\mu \alpha_{i}^{L} q_{i}^{L}+(1-\mu) \alpha_{i}^{H} q_{i}^{H}}-c\right)
$$

We will first consider the complete information case in which each consumer's type is known by both networks and networks can apply third degree price discrimination. We show that in this case firms will offer exactly the same two-part tariffs to light and heavy users. This then implies that the equilibrium under the complete information case is the equilibrium under incomplete information.

\footnotetext{
${ }^{17}$ We consider the case with two types merely for expositional simplicity. Our result can be easily extended to $m$ types with $m>2$.
} 
Network $i$ 's profit is given by:

$$
\begin{aligned}
\Pi_{i}= & \mu \alpha_{i}^{L}\left[\left(p_{i}^{L}-c\right) q_{i}^{L}+F_{i}^{L}-f\right]+(1-\mu) \alpha_{i}^{H}\left[\left(p_{i}^{H}-c\right) q_{i}^{H}+F_{i}^{H}-f\right] \\
& -\left(a_{i}-c_{0}\right)\left(\mu \alpha_{i}^{L} q_{i}^{L}+(1-\mu) \alpha_{i}^{H} q_{i}^{H}\right) \alpha_{j} \\
& +\left(a_{j}-c_{0}\right)\left(\mu \alpha_{j}^{L} q_{j}^{L}+(1-\mu) \alpha_{j}^{H} q_{j}^{H}\right) \alpha_{i} .
\end{aligned}
$$

We have

$$
\begin{aligned}
& \left(a_{j}-c_{0}\right)\left(\mu \alpha_{j}^{L} q_{j}^{L}+(1-\mu) \alpha_{j}^{H} q_{j}^{H}\right)= \\
& \quad \kappa\left\{\mu \alpha_{j}^{L}\left[F_{j}^{L}+\left(p_{j}^{L}-c\right) q_{j}^{L}\right]+(1-\mu) \alpha_{j}^{H}\left[F_{j}^{H}+\left(p_{j}^{H}-c\right) q_{j}^{H}\right]\right\} .
\end{aligned}
$$

Therefore,

$$
\begin{aligned}
\Pi_{i}= & \mu \alpha_{i}^{L}\left(1-\kappa \alpha_{j}\right)\left[\left(p_{i}^{L}-c\right) q_{i}^{L}+F_{i}^{L}\right]+(1-\mu)\left(1-\kappa \alpha_{j}\right) \alpha_{i}^{H}\left[\left(p_{i}^{H}-c\right) q_{i}^{H}+F_{i}^{H}\right] \\
& -\alpha_{i} f+\alpha_{i} \kappa\left\{\mu \alpha_{j}^{L}\left[F_{j}^{L}+\left(p_{j}^{L}-c\right) q_{j}^{L}\right]+(1-\mu) \alpha_{j}^{H}\left[F_{j}^{H}+\left(p_{j}^{H}-c\right) q_{j}^{H}\right]\right\} .
\end{aligned}
$$

It is convenient to maximize $\Pi_{i}$ with respect to $\left(p_{i}^{\theta}, w_{i}^{\theta}\right)$ instead of $\left(p_{i}^{\theta}, F_{i}^{\theta}\right)$. Then, we have:

$$
\begin{aligned}
\Pi_{i}= & \mu \alpha_{i}^{L}\left(1-\kappa \alpha_{j}\right)\left[\left(p_{i}^{L}-c\right) q_{i}^{L}+v_{L}\left(p_{i}^{L}\right)-w_{i}^{L}\right] \\
& +(1-\mu)\left(1-\kappa \alpha_{j}\right) \alpha_{i}^{H}\left[\left(p_{i}^{H}-c\right) q_{i}^{H}+v_{H}\left(p_{i}^{H}\right)-w_{i}^{H}\right]-\alpha_{i} f \\
& +\alpha_{i} \kappa \mu \alpha_{j}^{L}\left[v_{L}\left(p_{j}^{L}\right)-w_{j}^{L}+\left(p_{j}^{L}-c\right) q_{j}^{L}\right] \\
& +\alpha_{i} \kappa(1-\mu) \alpha_{j}^{H}\left[v_{H}\left(p_{j}^{H}\right)-w_{j}^{H}+\left(p_{j}^{H}-c\right) q_{j}^{H}\right] .
\end{aligned}
$$

Maximizing $\pi_{i}$ with respect to $p_{i}^{\theta}$ given $w_{i}^{\theta}$ leads to the marginal cost pricing for all $\alpha_{i}^{\theta}$ as long as $\kappa \leq 1$. When $p_{i}^{\theta}=p_{j}^{\theta}=c$ for $\theta=H, L$, we have

$$
\begin{aligned}
\Pi_{i}= & \mu \alpha_{i}^{L}\left(1-\kappa \alpha_{j}\right)\left[v_{L}(c)-w_{i}^{L}\right]+(1-\mu)\left(1-\kappa \alpha_{j}\right) \alpha_{i}^{H}\left[v_{H}(c)-w_{i}^{H}\right] \\
& -\alpha_{i} f+\alpha_{i} \kappa\left\{\mu \alpha_{j}^{L}\left[v_{L}(c)-w_{j}^{L}\right]+(1-\mu) \alpha_{j}^{H}\left[v_{H}(c)-w_{j}^{H}\right]\right\} .
\end{aligned}
$$

Taking derivatives and solving for a symmetric solution (i.e., $w_{i}^{\theta}=w_{j}^{\theta}$ for $\theta=L, H$ ) yields

$$
w_{i}^{\theta}=v_{\theta}-f+\frac{\kappa-2}{4 \sigma}
$$


so that

$$
F_{i}^{\theta}=f+\frac{2-\kappa}{4 \sigma}
$$

Since the optimal fixed fee is identical for both consumer types when firms can discriminate between types, it will be optimal in the case of incomplete information to offer only one two-part tariff $T=F+c q$ where

$$
F=\frac{2-\kappa}{4 \sigma}
$$

Note also that the equilibrium two-part tariff is identical to the one in the case of homogeneous consumers in section 4.1. Summarizing, we have:

Proposition 6 In the Hotelling model of LRT (1998a), suppose that consumers are heterogeneous (some are light consumers and others are heavy consumers) and that networks compete in menus of two-part tariffs without knowing each consumer's type.

(i) For any $\kappa \leq 1$, each network chooses the variable price equal to the marginal cost for all types of consumers.

(ii) Given $\kappa \leq 1$, in symmetric equilibrium, both networks offer an identical two-part tariff $\left(p=c, F=\frac{2-\kappa}{4 \sigma}\right)$ for all types of consumers.

Dessein (2003) and Hahn (2004) find that when $a=c_{0}$ (i.e., $\kappa=0$ ), both networks offer an identical two-part tariff $\left(p=c, F=\frac{1}{2 \sigma}\right)$ for all types of consumers. In fact, if $a=c_{0}$, as can be seen in (17), access price disappears from the profit function and the profit function becomes the same as the one in a standard Hotelling model without interconnection. This is why they rediscover the efficient two-part tariff result obtained by Armstrong and Vickers (2001) and Rochet and Stole (2002) in the context of competitive price discrimination without interconnection between firms. In other words, $a=c_{0}$ achieves efficiency by making the case with interconnection similar to the case without interconnection. What we show is that in the presence of interconnection, there is a class of access pricing rules which achieve efficiency. Hence, interconnection provides extra instruments to achieve the static efficiency as long as we make access prices depend on retail prices.

\subsubsection{Asymmetric brand loyalty}

In this subsection we consider our access pricing rule when two networks compete in two part tariffs but one of the networks has an "incumbent" advantage in that it offers an extra surplus to its customers. One can think of this as asymmetric brand loyalty. We follow the modelling of Carter and Wright $(1999,2003)$. That is, we will employ the two firm Hotelling 
model where consumers obtain extra surplus $\beta /(2 \sigma) \geq 0$ from subscribing to network 1 . Transportation cost equals $t=1 /(2 \sigma)$. We maintain the assumption of full coverage and do not allow for termination based price discrimination.

We find that firms always will want to set variable price equal to marginal cost $c$, independent of $\kappa$ and their market shares, for all $\kappa \leq 1$. Moreover, the equilibrium market shares will be independent of $\kappa$.

Given two part tariff $\left(p_{i}, F_{i}\right)$, the net surplus of a consumer of network $i$ is given by:

$$
w_{i}=v\left(p_{i}\right)-F_{i}
$$

Given the extra surplus from subscribing to network 1, the customer located at $x$ is indifferent between the two networks if and only if $w_{1}+\beta /(2 \sigma)-t x=w_{2}-t(1-x)$. Hence, if both networks have positive market shares, market share of network 1 equals

$$
\alpha_{1}=\frac{\beta+1}{2}+\sigma\left(w_{1}-w_{2}\right)
$$

and network 2 has market share $\alpha_{2}=1-\alpha_{1}$.

We have the following expression for network $i$ 's profit:

$$
\Pi_{i}\left(p_{i}, F_{i}\right)=\alpha_{i}\left\{\left[p_{i}-c-\left(1-\alpha_{i}\right)\left(a_{i}-c_{0}\right)\right] q\left(p_{i}\right)+F_{i}-f+\alpha_{j}\left(a_{j}-c_{0}\right) q\left(p_{j}\right)\right\} .
$$

In particular, from (13) the total access payment mark-up that network $i$ makes to network $j$ is given by:

$$
\alpha_{i}\left(1-\alpha_{i}\right)\left(a_{i}-c_{0}\right) q\left(p_{i}\right)=\alpha_{i} \kappa\left(1-\alpha_{i}\right) \pi_{i}
$$

where $\pi_{i}=\left(p_{i}-c\right) q\left(p_{i}\right)+F_{i}$. Therefore, the arguments we made in section 4.1 apply to the competition among asymmetric networks: as long as $\left(1-\kappa\left(1-\alpha_{i}\right)\right) \geq 0$ (which is satisfied when $\kappa \leq 1$ ), the profit maximization with respect to $p_{i}$ for given $w_{i}$ leads to marginal cost pricing $\left(i . e ., p_{i}=c\right)$ for any $\alpha_{i}$ and for any $\kappa \leq 1$.

The following proposition characterizes the equilibrium of the competition among asymmetric networks.

Proposition 7 When $0 \leq \kappa \leq 1,0<\beta<3, \beta \kappa<1$ and $\sigma(>0)$ is small enough, there exists a unique equilibrium in which networks charge variable price $p=c$ and fixed fees

$$
F_{1}=f+\frac{6+2 \beta-3 \kappa-\beta^{2} \kappa}{12 \sigma}
$$


and

$$
F_{2}=f+\frac{6-2 \beta-3 \kappa-\beta^{2} \kappa}{12 \sigma}
$$

Market share for firm 1 equals $\alpha_{1}=(3+\beta) / 6$. Equilibrium profits are

$$
\Pi_{1}=\alpha_{1}\left(F_{1}-f\right)+\alpha_{1}\left(1-\alpha_{1}\right) \kappa\left(F_{2}-F_{1}\right)=\frac{(3+\beta)^{2}}{216 \sigma}(6-\kappa(3+\beta))
$$

and

$$
\Pi_{2}=\alpha_{2}\left(F_{2}-f\right)+\alpha_{2}\left(1-\alpha_{2}\right) \kappa\left(F_{1}-F_{2}\right)=\frac{(3-\beta)^{2}}{216 \sigma}(6-\kappa(3-\beta)) .
$$

Hence, for any $0 \leq \kappa \leq 1$ we obtain efficient pricing. By varying $\kappa$ we can address and achieve further objectives, without distorting the efficient marginal cost pricing result. An increase in $\kappa$ promotes competition in terms of the fixed fee and thereby decreases the profits of each network. Therefore, by increasing $\kappa$, the regulator or competition authority can improve consumer welfare.

Access prices are not reciprocal, unless $\kappa=0$. Both networks price at marginal cost but since the incumbent network sets a higher fixed fee, he has a higher average retail price and thus he will pay higher per minute access charges than the rival network. Note that equilibrium market shares are independent of $\kappa$. In particular, equilibrium market shares are the same as in Carter and Wright (2003), which basically corresponds to the case of $\kappa=0$. Namely, Carter and Wright (2003) argue in favor of a rule that allows the incumbent to choose the reciprocal access price, since it will choose access price equal to the marginal cost of terminating a call.

More generally, we can consider non-reciprocal access pricing rules for asymmetric networks. For instance, in our rule, we can make $\kappa$ depend on a firm's identify (i.e. $\kappa_{i}$ for firm i). Hence, we have:

$$
\begin{gathered}
\alpha_{i}\left(1-\alpha_{i}\right)\left(a_{i}-c_{0}\right) q\left(p_{i}\right)=\alpha_{i}\left(1-\alpha_{i}\right) \kappa_{i} \pi_{i} ; \\
\prod_{i}\left(p_{i}, F_{i}\right)=\alpha_{i}\left\{\left[1-\kappa_{i}\left(1-\alpha_{i}\right)\right] \pi_{i}-f+\kappa_{j}\left(1-\alpha_{i}\right) \pi_{j}\right\}
\end{gathered}
$$

where $\pi_{i}=\left(p_{i}-c\right) q\left(p_{i}\right)+F_{i}$. Therefore, firm $i$ chooses $p_{i}=c$ for any $\alpha_{i}>0$ and $\kappa_{i} \leq 1$. We conjecture that by properly choosing $\left(\kappa_{1}, \kappa_{2}\right)$ the regulator can achieve the socially efficient distribution of market shares but analyzing this is beyond the scope of this paper. 


\section{Conclusion}

We proposed a new approach, a retail benchmarking approach, to determine efficient access prices for interconnected networks. Our approach is simple since we consider a set of linear access pricing rules that linearly links the mark-up of the access price that network $i$ pays to its rivals with network $i$ 's retail price mark-up. Our approach is not informationally demanding since the regulator only needs to know the marginal costs of communication. We showed that the efficient access pricing rules that we discovered with the benchmarking approach have some remarkable properties with respect to what we can do with the standard approach of fixed access prices.

First, when networks compete in linear prices without network based price discrimination, under the standard approach (i.e., in LRT, 1998a), determining the Ramsey access price, which is below termination cost, is informationally demanding. Since the Ramsey access price depends on demand elasticity, the level of the Ramsey retail price and the level of the monopoly retail price, the regulator needs to know not only the marginal costs but also the fixed cost and the demand structure. In contrast, under our approach, there is a simple access pricing rule that achieves the Ramsey outcome as the unique equilibrium independently of the underlying demand conditions. Our rule is not informationally demanding since the regulator only needs to know the marginal costs.

Second, when networks compete in two-part tariffs in an otherwise similar framework, the literature has obtained a static efficiency and a profit neutrality result. The static efficiency result says that setting access price equal to the termination cost leads to marginal cost pricing. The profit neutrality result says that firms' equilibrium profits are equal to the Hotelling profits for any access price. These two results provide a rationale for letting firms choose collectively the access price as they do not have strict incentives to set a higher access price. However, in the same setting, Valletti and Cambini (2005) find that when firms can invest in the quality of their networks prior to setting prices, firms have an incentive to choose an access charge larger than the termination cost in order to reduce investment incentives. The reason is that their equilibrium profits gross of the investment costs are equal to the Hotelling profits, because of the profit neutrality result. Furthermore, they show that static efficiency is in conflict with dynamic efficiency since firms under-invest in quality when access price is equal to the termination cost.

We considered a particular class of access pricing rules under which the mark-up of the access price that network $i$ pays to its rivals is a fraction of network $i$ 's average retail 
price mark-up. We first showed that all of the rules in the class lead to static efficiency (i.e., marginal cost pricing) while the profits vary depending on the degree with which the average retail price mark-up influences the access price mark-up. Therefore, by properly choosing this degree, the regulator can pursue additional objectives such as improving consumer surplus or inducing full coverage: in particular, both static efficiency in terms of retail prices and dynamic efficiency in terms of investment can be achieved at the same time.

A general lesson from our approach is that benchmarking access prices to retail prices provide extra instruments to promote competition and efficiency. In particular, our optimal access pricing rules intensify retail competition since a network can reduce its access payment to rival firms by reducing its own retail tariff(s). In the future, we plan to study how our approach can be adapted to the case of network-based price discrimination.

\section{Appendix}

\section{Proof of Proposition 1}

We here complete the proof of Proposition 1 by proving that no asymmetric pure strategy equilibria exist when firms compete in linear prices.

Lemma 1 Property 5 implies that for any firm $i$ with positive market share $\alpha_{i}>0$

$$
\frac{\partial \Pi_{i}}{\partial p_{i}}=\frac{\partial \alpha_{i}}{\partial p_{i}}\left(\frac{\Pi_{i}}{\alpha_{i}}\right)+\frac{\alpha_{i} R^{\prime}\left(p_{i}\right) n}{n-1}\left(\alpha_{i}-1 / n\right)-\frac{\partial \alpha_{i} / \partial p_{i}}{1-\alpha_{i}}\left(\Pi_{i}-\alpha_{i}\left(R\left(p_{i}\right)-f\right)\right) .
$$

Proof. Let $i, j, k$ represent three different firms. On the one hand, from property 5 , we have, for any $\alpha_{j}>0$

$$
\frac{\partial \alpha_{k}}{\partial p_{i}}=\frac{\alpha_{k}}{\alpha_{j}} \frac{\partial \alpha_{j}}{\partial p_{i}}
$$

On the other hand, from $\alpha_{i}+\sum_{k \neq i} \alpha_{k}=1$, we have

$$
\frac{\partial \alpha_{i}}{\partial p_{i}}+\sum_{k \neq i} \frac{\partial \alpha_{k}}{\partial p_{i}}=0
$$

By substituting (20) into (21), we get

$$
\frac{\partial \alpha_{j}}{\partial p_{i}}=-\frac{\alpha_{j}}{1-\alpha_{i}} \frac{\partial \alpha_{i}}{\partial p_{i}}
$$

Result (19) is now easily obtained by using (22) when computing $\frac{\partial \Pi_{i}}{\partial p_{i}}$. 
Proposition 8 There is no asymmetric equilibrium (in pure strategies).

Proof. Suppose there is an asymmetric equilibrium p. Without loss of generality, we can assume $p_{1} \leq p_{2} \leq \ldots \leq p_{n}$ with $p_{1}<p_{n}$. Symmetry and monotonicity then imply that $\alpha_{1} \geq \alpha_{2} \geq \ldots \geq \alpha_{n}$ with $\alpha_{1}>1 / n>\alpha_{n}$ by the full coverage property.

Claim: There is no "cornered-market" equilibrium.

Proof of Claim: First, suppose that network 1 corners the market with $\pi_{1}>0$. Then, network 2 , for instance, can charge $p_{2}=p_{1}$ and make a profit $\pi_{1} / 2>0$ and therefore we get a contradiction.

Next, suppose that network 1 corners the market with $\pi_{1}=0$. This implies that $p_{1}=p^{R}$ or $p_{1}=\bar{p}$. If $p_{1}=\bar{p}$, it follows from Property 4 that network 2 can realize a strictly positive profit by charging $p_{2}=p^{m}$. Hence, we must have $p_{1}=p^{R}$ and $p_{2}>p^{R}$. However, this cannot be an equilibrium either since Lemma 1 then implies that network 1 can increase its profit as $\Pi_{1}^{\prime}\left(p^{R}\right)=R^{\prime}\left(p^{R}\right)>0$.

Claim: All firms have positive market share.

Proof of Claim: Suppose not. Then $\alpha_{n}=0$.

Case A: There is a firm $i$ with $\alpha_{i}\left(R\left(p_{i}\right)-f\right)>0$.

Clearly, firm $i$ must make nonnegative profits in equilibrium and its market share is strictly less than 1 . Hence,

$$
0 \leq \frac{\Pi_{i}}{\alpha_{i}\left(1-\alpha_{i}\right)}=\frac{R\left(p_{i}\right)-f}{1-\alpha_{i}}+\frac{n}{n-1} \sum_{j \neq i} \frac{\alpha_{j}}{1-\alpha_{i}}\left(R\left(p_{j}\right)-R\left(p_{i}\right)\right) .
$$

If firm $n$ deviates and sets price $p_{i}\left(<p_{n}\right)$, firm $n$ and firm $i$ will have the same market share and profits, by the symmetry property. We will show that these firms jointly will have strictly positive profits, which then implies that the deviation by firm $n$ is profitable. Let $\hat{p}$ denote the price vector after the deviation by firm $n$. Let $\hat{\alpha}_{k}=\alpha_{k}(\hat{p})$ and $\hat{\Pi}_{k}=\Pi_{k}(\hat{p})$. Note that since the market share of any firm $j \neq n, i$ will decrease, the sum of the market shares of firms $i$ and $n$ will be higher than the market share of firm $i$ before the deviation: $\hat{\alpha}_{i}+\hat{\alpha}_{n}>\alpha_{i}$. We have

$$
\hat{\Pi}_{i}+\hat{\Pi}_{n}=\left(\hat{\alpha}_{i}+\hat{\alpha}_{n}\right)\left(R\left(p_{i}\right)-f+\frac{n}{n-1} \sum_{j} \hat{\alpha}_{j}\left(R\left(p_{j}\right)-R\left(p_{i}\right)\right)\right)
$$


so that

$$
\frac{2 \hat{\Pi}_{n}}{2 \hat{\alpha}_{n}\left(1-2 \hat{\alpha}_{n}\right)}=\frac{R\left(p_{i}\right)-f}{1-\hat{\alpha}_{i}-\hat{\alpha}_{n}}+\frac{n}{n-1} \sum_{j \neq i, j \neq n} \frac{\hat{\alpha}_{j}}{1-\hat{\alpha}_{i}-\hat{\alpha}_{n}}\left(R\left(p_{j}\right)-R\left(p_{i}\right)\right) .
$$

Because of Property 5, the second term on the r.h.s. is equal to the second term on the r.h.s of equation (23). Hence,

$$
\frac{2 \hat{\Pi}_{n}}{2 \hat{\alpha}_{n}\left(1-2 \hat{\alpha}_{n}\right)}=\left(R\left(p_{i}\right)-f\right)\left(\frac{1}{1-\hat{\alpha}_{i}-\hat{\alpha}_{i}}-\frac{1}{1-\alpha_{i}}\right)+\frac{\Pi_{i}}{\alpha_{i}\left(1-\alpha_{i}\right)}>0 .
$$

The inequality follows since $\Pi_{i} \geq 0$ and both factors in the first term are strictly positive. This shows that the firm without market share has an incentive to deviate and fix price equal to the price of a firm that has positive market share and strictly positive net revenue per consumer.

Case B: There is no firm $i$ with $\alpha_{i}\left(R\left(p_{i}\right)-f\right)>0$.

In this case all firms with positive market share have zero net revenue and profits, since the sum of firms' profits equals the average net revenue $\left(\sum \Pi_{j}=\sum \alpha_{j}\left(R\left(p_{j}\right)-f\right)\right)$. This implies that all firms with positive market share set either price $p^{R}$ or $\bar{p}$. However, this is impossible since a firm that sets $p^{R}$ has an incentive to increase its price when its market share is strictly higher than $1 / n$. (Its market share is at least $1 /(n-1)$ as it sets the lowest price and firm $n$ is supposed to have zero market share.)

$$
\frac{\partial \Pi}{\partial p_{i}}=\frac{\partial \alpha_{i}}{\partial p_{i}}\left(\frac{\Pi}{\alpha_{i}}\right)+\alpha_{i} \frac{n}{n-1} R^{\prime}\left(p^{R}\right)\left(\alpha_{i}-1 / n\right)-\frac{\partial \alpha_{i} / \partial p_{i}}{1-\alpha_{i}}\left(\Pi_{i}-\alpha_{i}\left(R\left(p^{R}\right)-f\right)>0\right.
$$

since the first and third term are zero and the second is strictly positive. But if all firms except firm $n$ set $\bar{p}$, firm $n$ can deviate and set $p$ slightly above $p^{R}$ and make positive profits. Namely, if he deviates and sets price equal to $p^{R}$ he will make zero profit, but his marginal profit at these prices will then be strictly positive by the same argument as before.

The above shows that all firms must have positive market share in equilibrium. Note that no firm $j$ can charge $p^{m}$ in equilibrium. For such a firm $R^{\prime}\left(p^{m}\right)=0$ and $R\left(p_{j}\right) \geq R\left(p_{i}\right)$ for all $i$ with strict inequality for at least some $i$. This implies then that this firm has an incentive to lower its price as his marginal profit is strictly negative. (See equation (19)).We now distinguish three possible cases: (I) all firms set price below $p^{m}$; (II) all firms set price above $p^{m}$; and (III) some set price below $p^{m}$ and some set a price above $p^{m}$. We will derive a contradiction in all three cases, which then concludes the proof that no asymmetric 
equilibrium exists.

Case I: $p_{n}<p^{m}$. In this case all firms set a price below the monopoly price and thus $R\left(p_{n}\right) \geq R\left(p_{j}\right)$ for all $j$ with strict inequality for some $j$ (e.g. $j=1$ ). Hence, $\Pi_{n}<$ $\alpha_{n}\left(R\left(p_{n}\right)-f\right)$. Moreover, $R^{\prime}\left(p_{n}\right)>0$. Equation (19) implies then that

$$
\frac{\partial \Pi_{n}}{\partial p_{n}}<0
$$

Hence, firm $n$ can improve his profits by lowering its price.

Case II: $p_{1}>p^{m}$. In this case $R\left(p_{1}\right) \geq R\left(p_{j}\right)$ for all $j$ with strict inequality for some $j$ (e.g. $j=n$ ). Hence, $\Pi_{1}<\alpha_{1}\left(R\left(p_{1}\right)-f\right)$. Moreover, $R^{\prime}\left(p_{1}\right)<0$. Equation (19) implies then that

$$
\frac{\partial \Pi_{1}}{\partial p_{1}}<0
$$

Hence, firm 1 can improve his profits by lowering its price.

Case III: For some $1 \leq i<n$ we have $p_{i}<p^{m}<p_{i+1}$. If all firms have the same (net) revenue per consumer, the net balance of access prices equals zero for all firms, and profits are equal to market share times net revenue per consumer. If this profit is equal to zero, firms $j \leq i$ have $p_{j}=p^{R}$ and firms $j>i$ have $p_{j}=\bar{p}$. However, then the marginal profit for firm 1 (for example) is strictly positive as the first and third term in (19) are zero and the second term is strictly positive. Hence, if all firms have the same net revenue, net revenues (and thus profits) have to be strictly positive for all firms.

Firms $j \leq i$ set some price $p \in\left(p^{R}, p^{m}\right)$ and firms $j>i$ set some price $p^{\prime} \in\left(p^{m}, \bar{p}\right)$ where $R(p)=R\left(p^{\prime}\right)>f$. However, firm $n$ (for example) could profitably deviate from $p^{\prime}$ to $p$. This would not affect the net balance of access prices (which remains equal to zero) and would also not change his strictly positive net revenue per consumer. However, it would increase his market share, and therefore its profit. Therefore, we conclude that not all firms make the same net revenue per consumer. This of course implies that the firm with the highest net revenue per customer has a negative net balance of access prices.

The firm with the highest net revenue per customer, $R\left(p_{j}\right)-f$, must be either firm $i$ or firm $i+1$. As argued above, its net balance of access prices must be strictly negative. Since its profit in equilibrium must be nonnegative, this means that it must make a strictly positive net revenue per consumer, so that its price is strictly between $p^{R}$ and $\bar{p}$. We now claim that it cannot be that firm $i+1$ has (weakly) higher net revenue per customer than any other firm. Namely, if that were the case, firm $i+1$ could deviate to $p^{\prime}$ where $p^{\prime}$ is defined 
as the unique price less than $p^{m}$ with $R\left(p^{\prime}\right)=R\left(p_{i+1}\right)$. This would increase its market share, and decrease the market share of any other firm by the same percentage (by Property 5). This means that its profit per customer $\Pi_{i+1} / \alpha_{i+1}$ increases, since its net balance from access prices becomes less negative. But this then also implies that total profits increase, as its market share increases as well.

Hence, firm $i$ has the highest net revenue per customer and $R\left(p_{i}\right)>R\left(p_{j}\right)$ for any $j>i$ and $R\left(p_{i}\right)>f$. Note that from (19) it follows immediately that $\alpha_{i}>1 / n$, since otherwise the marginal profit would be strictly negative and firm $i$ would have an incentive to lower its price.

We now show that if $j>i$ then $p_{j}>\bar{p}$. Suppose not. We will show that then firm $j$ will gain by deviating to setting price $p_{i}$. Namely, for any firm $k$ we have the following expression for profits per on-net consumer and per off-net consumer

$$
\frac{\Pi_{k}}{\alpha_{k}\left(1-\alpha_{k}\right)}=\left(R\left(p_{k}\right)-f\right)\left(\frac{1}{1-\alpha_{k}}-\frac{n}{n-1}\right)+\frac{n}{n-1} \sum_{j \neq k} \frac{\alpha_{j}}{1-\alpha_{k}}\left(R\left(p_{j}\right)-f\right) .
$$

Note that the last term does not change when $p_{k}$ is varied. Consider now $k>i$. If we lower $p_{k}$ till $\tilde{p}_{k}=p_{i}$, revenue per customer goes up from $R\left(p_{k}\right)-f \geq 0$ till $R\left(p_{i}\right)-f>R\left(p_{k}\right)-f$. Moreover, market share of firm $k$ will increase and thus the second factor in the first term will increase. This implies that

$$
\frac{\tilde{\Pi}_{k}}{\tilde{\alpha}_{k}\left(1-\tilde{\alpha}_{k}\right)}>\frac{\Pi_{k}}{\alpha_{k}\left(1-\alpha_{k}\right)}
$$

where $\tilde{\Pi}_{k}$ and $\tilde{\alpha}_{k}$ denote profit and market share of firm $k$ after the deviation. Since, firm $k$ and firm $i$ will have the same market share after the deviation, we must have $1 / 2 \geq \tilde{\alpha}_{k}$ and we know $\tilde{\alpha}_{k}>\alpha_{k}$. Therefore, we have $0<\alpha_{k}\left(1-\alpha_{k}\right)<\tilde{\alpha}_{k}\left(1-\tilde{\alpha}_{k}\right)$. It follows that

$$
\tilde{\Pi}_{k}=\tilde{\alpha}_{k}\left(1-\tilde{\alpha}_{k}\right) \frac{\tilde{\Pi}_{k}}{\tilde{\alpha}_{k}\left(1-\tilde{\alpha}_{k}\right)}>\tilde{\alpha}_{k}\left(1-\tilde{\alpha}_{k}\right) \frac{\Pi_{k}}{\alpha_{k}\left(1-\alpha_{k}\right)}>\Pi_{k} .
$$

Hence, the deviation is profitable.

However, Property 4 implies that $\alpha_{j}(p)=0$ when $p_{i}<p^{m}$ and $p_{j}>\bar{p}$.

This completes the proof of Proposition 8.

\section{Proof of Proposition 3}

Since (i) is proven in the text before the proposition, we only need to prove (ii). We first derive the unique symmetric equilibrium candidate. We will then derive conditions under 
which this candidate equilibrium is indeed an equilibrium.

Using $v^{\prime}\left(p_{i}\right)=-q\left(p_{i}\right)$ we obtain

$$
\partial \prod_{i} / \partial p_{i}=\alpha_{i} q^{\prime}\left(p_{i}\right)\left(p_{i}-c\right)\left(1-\kappa\left(1-\alpha_{i}\right)\right)
$$

When $1-\kappa\left(1-\alpha_{i}\right)>0$ and $\alpha_{i}>0$, this derivative is negative (positive) when $p_{i}>c$ $\left(p_{i}<c\right.$, respectively). Hence, the equilibrium price in a symmetric equilibrium must be equal to marginal cost $c$.

We now focus on the derivative of profit with respect to $w_{i}$.

$$
\frac{\partial \Pi_{i}}{\partial w_{i}}=\sigma\left[\frac{\Pi_{i}}{\alpha_{i}}\right]+\alpha_{i}\left(-1+\kappa\left(1-\alpha_{i}\right)+\kappa \sigma\left[F_{i}+R\left(p_{i}\right)-F_{j}-R\left(p_{j}\right)\right]\right)
$$

In a symmetric interior equilibrium (i.e. $p_{i}=p$ and $F_{i}=F$ ), we have $p=c$ and thus $\Pi_{i}=(F-f) / 2$. Hence, the first order condition gives

$$
0=\sigma(F-f)+\frac{1}{2}(-1+\kappa / 2)
$$

The symmetric equilibrium candidate has thus

$$
F=f+\frac{2-\kappa}{4 \sigma}
$$

Symmetric equilibrium profit per firm equals

$$
\Pi^{*}=\frac{2-\kappa}{8 \sigma}
$$

We see that a necessary condition is $\kappa \leq 2$. The second order derivative yields

$$
\frac{\partial^{2} \Pi_{i}}{\partial w_{i}^{2}}=2 \sigma\left[-1+\kappa \sigma\left(R\left(p_{i}\right)+v\left(p_{i}\right)-3 w_{i}-R\left(p_{j}\right)-v\left(p_{j}\right)+3 w_{j}\right)\right]
$$

At the symmetric equilibrium candidate this is equal to $-2 \sigma$ and thus strictly negative for all $\kappa$.

We now derive sufficient and necessary conditions for the symmetric equilibrium candidate $T=F+c q$ to be indeed an equilibrium.

Hence, let $p_{2}=c$ and $F_{2}=F$. That is, $w_{2}=v(c)-F=v(c)-f+(\kappa-2) /(4 \sigma)$. First, we know from (24) that, as long as $1-\kappa\left(1-\alpha_{1}\right)>0$, it is optimal to set $p_{1}=c$. This is the case when $\kappa \leq 1$ and $\alpha_{i}>0$. The optimal $w_{1}$ is then found by the first order condition at 
$w_{1}=w_{2}$, since the second order derivative $\left(2 \sigma\left(-1+3 \kappa \sigma\left(w_{2}-w_{1}\right)\right)\right)$ is strictly negative for all $w_{1} \geq 0$ as long as $\sigma$ is small enough.

On the other hand, if $\kappa>1$, network 1 can obtain unbounded profits by choosing $w_{1}$ such that $1-\kappa\left(1-\alpha_{1}\right)<0$ by letting $p_{1} \approx 0$. (Namely, if demand is as in LRT, then $\lim _{p_{1} \rightarrow 0} v\left(p_{1}\right)+R\left(p_{1}\right)=-\infty$, and profit is unbounded from equation (15)).

It is not hard to see that there cannot be an asymmetric equilibrium. Namely, from (24) we know that both firms will set $p_{j}=c$. Substituting these prices and taking derivatives with respect to $w_{i}$ yields

$$
\frac{\partial \Pi_{i}}{\partial w_{i}}=\sigma\left[v(c)-w_{i}-f\right]+\sigma \kappa\left(1-2 \alpha_{i}\right)\left(w_{i}-w_{j}\right)-\alpha_{i}\left(1-\kappa\left(1-\alpha_{i}\right)\right)
$$

Subtracting the first order derivative for firm $j$ from that for firm $i$ yields

$$
0-0=\frac{\partial \Pi_{i}}{\partial w_{i}}-\frac{\partial \Pi_{j}}{\partial w_{j}}=-3 \sigma\left(w_{i}-w_{j}\right)
$$

so that $w_{i}=w_{j}$. This shows that there cannot be interior asymmetric equilibrium.

We now show that there is no cornered market equilibrium. Suppose, for instance, that firm 1 corners the market. Then, we must have:

$$
\left.\frac{\partial \Pi_{1}}{\partial w_{1}}\right|_{\alpha_{1}=1}=\sigma\left[v(c)-w_{1}-f\right]-\sigma \kappa\left(w_{1}-w_{2}\right)-1 \geq 0
$$

and

$$
\left.\frac{\partial \Pi_{2}}{\partial w_{2}}\right|_{\alpha_{2}=0}=\sigma\left[v(c)-w_{2}-f\right]-\sigma \kappa\left(w_{1}-w_{2}\right) \leq 0 .
$$

The two inequalities are equivalent to

$$
v(c)-w_{2}-f \leq \kappa\left(w_{1}-w_{2}\right) \leq v(c)-w_{1}-f-\frac{1}{\sigma}
$$

This implies

$$
w_{1}-w_{2} \leq-\frac{1}{\sigma}
$$

which contradicts $\alpha_{1}>\alpha_{2}$ since one cannot have $\alpha_{1}>\alpha_{2}$ without satisfying $w_{1}-w_{2}>0$.

\section{Proof of Proposition 7}

We already explained why the equilibrium price in any equilibrium must be equal to marginal cost $c$. We now focus on the derivative of profit with respect to $w_{i}$, given $p_{1}=p_{2}=$ 
c.

$$
\left.\frac{\partial \Pi_{i}}{\partial w_{i}}=\sigma\left[\frac{\Pi_{i}}{\alpha_{i}}\right]+\alpha_{i}\left(-1+\kappa\left(1-\alpha_{i}\right)+\kappa \sigma\left[w_{j}-w_{i}\right)\right]\right)
$$

Hence,

$$
0=\frac{\partial \Pi_{1}}{\partial w_{1}}=\sigma\left(v(c)-w_{1}-f\right)+\sigma \kappa\left(w_{1}-w_{2}\right)\left(1-2 \alpha_{1}\right)-\alpha_{1}+\kappa \alpha_{1}\left(1-\alpha_{1}\right)
$$

and

$$
0=\frac{\partial \Pi_{2}}{\partial w_{2}}=\sigma\left(v(c)-w_{2}-f\right)+\sigma \kappa\left(w_{2}-w_{1}\right)\left(1-2 \alpha_{2}\right)-\alpha_{2}+\kappa \alpha_{2}\left(1-\alpha_{2}\right)
$$

Subtracting (28) from (27) yields

$$
0=\sigma\left(w_{2}-w_{1}\right)-2 \alpha_{1}+1
$$

Combining (18) and (29) yields the result $\alpha_{1}=(3+\beta) / 6$. The expressions for fixed fees and profits follow now immediately from (27) and (28).

The second order derivative (at $p_{1}=p_{2}=c$ ) yields

$$
\frac{\partial^{2} \Pi_{1}}{\partial w_{1}^{2}}=-2 \sigma\left[1+\beta \kappa+3 \kappa \sigma\left(w_{1}-w_{2}\right)\right]
$$

while

$$
\frac{\partial^{2} \Pi_{2}}{\partial w_{2}^{2}}=-2 \sigma\left[1-\beta \kappa+3 \kappa \sigma\left(w_{2}-w_{1}\right)\right] .
$$

At the equilibrium candidate both expressions are equal to $-2 \sigma<0$.

We now derive sufficient and necessary conditions for the equilibrium candidate to be indeed an equilibrium.

Fix network 2's prices $p_{2}=c$ and $F_{2}$ as stated in the proposition. We know from (24) that, as long as $1-\kappa\left(1-\alpha_{1}\right)>0$, it is optimal for network 1 to set $p_{1}=c$. This is the case when $\kappa \leq 1$ and $\alpha_{i}>0$. The optimal $w_{1}$ is then found by the first order condition at $w_{1}=v(c)-F_{1}$, since the second order derivative $\left(-2 \sigma\left(1+\beta \kappa+3 \kappa \sigma\left(w_{1}-w_{2}\right)\right)\right)$ is strictly negative for all $w_{1} \geq 0$ as long as $\sigma$ is small enough. Similar reasoning applies when one fixes the prices of network 1 and optimizes for network 2, as long as $\beta \kappa<1$. (Note that the second order derivative for network 2 reads $-2 \sigma\left(1-\beta \kappa+3 \kappa \sigma\left(w_{2}-w_{1}\right)\right)$.)

It is not hard to see that there cannot be any other equilibrium. The only other possibility would be a cornered market equilibrium. If network 2 corners the market and obtains positive profit, then network 1 could deviate and use the same tariff and obtain positive profits. If 
network 2 corners the market but receives zero profit, then $F_{2}=f$ and $p_{2}=c$. If $\beta>1$, network 1 can set $p_{1}=c$ and $F_{1}=f+(\beta-1) /(2 \sigma)$, capture the whole market and make profits $F_{1}-f>0$. If $\beta \leq 1$, network 1 can set $p_{1}=c$ and $F_{1}=f+\varepsilon$, obtain market share $\alpha_{1}=(\beta+1) / 2-\varepsilon \sigma \in(0,1)$ and make profits per customer equal to $\varepsilon\left(1-\kappa\left(1-\alpha_{1}\right)\right)>0$.

Suppose now that network 1 corners the market. Suppose, for instance, that firm 1 corners the market. Then, we must have:

$$
\left.\frac{\partial \Pi_{1}}{\partial w_{1}}\right|_{\alpha_{1}=1}=\sigma\left[v(c)-w_{1}-f\right]-\sigma \kappa\left(w_{1}-w_{2}\right)-1 \geq 0
$$

and

$$
\left.\frac{\partial \Pi_{2}}{\partial w_{2}}\right|_{\alpha_{2}=0}=\sigma\left[v(c)-w_{2}-f\right]-\sigma \kappa\left(w_{1}-w_{2}\right) \leq 0 .
$$

The two inequalities are equivalent to

$$
v(c)-w_{2}-f \leq \kappa\left(w_{1}-w_{2}\right) \leq v(c)-w_{1}-f-\frac{1}{\sigma}
$$

This implies

$$
w_{1}-w_{2} \leq-\frac{1}{\sigma}
$$

which contradicts $\left(\alpha_{1}=1, \alpha_{2}=0\right)$ for $\beta<3$ since $\left(\alpha_{1}=1, \alpha_{2}=0\right)$ requires $w_{1}-w_{2} \geq$ $(1-\beta) /(2 \sigma)$.

\section{References}

Armstrong, M. "Network Interconnection." Economic Journal, Vol. 108 (1998): $545-564$

Armstrong, M. "The Theory of Access Pricing and Interconnection." in M. Cave, S. Majumdar and I. Vogelsang, eds., Handbook of Telecommunications Economics, chap. 8, North Holland, 2002.

Armstrong, M. and J. Vickers. "Competitive Price Discrimination", Rand Journal of Economics, Vol. 32 (2001): 579-605.

Australian Consumer and Competition Commission (2001). Pricing Methodology for the GSM Termination: Final Report.

Australian Consumer and Competition Commission (2004). Mobile Services Review: Mobile Terminating Access Service. 
Baumol, W. "Some Subtle Issues in Railroad Regulation," International Journal of Transport Economics Vol. 10 (1983): 341-355.

Baumol, W. and G.J. Sidak. "The Pricing of Inputs sold to Competitors," Yale Journal on Regulation, Vol. 11 (1994): 171-202.

Carter, M. and J. Wright. "Interconnection in Network Industries." Review of Industrial Organization, Vol. 14 (1999): 1-25.

Carter, M. and J. Wright. "Asymmetric Network Interconnection." Review of Industrial Organization, Vol. 22 (2003): 27-46.

Dessein, W. "Network Competition in Nonlinear Pricing." Rand Journal of Economics, Vol. 34 (2003): 593-611.

Dessein, W. "Network Competition with Heterogeneous Customers and Calling Patterns." Information Economics and Policy, Vol. 16 (2004): 323-345.

Doganoglu, T. and Y. Tauman. "Network Competition and Access Charge Rules." The Manchester School, Vol. 70 (2002): 16-35.

Economides, N. and L.J. White. "Access and Interconnection Pricing: How Efficient is the "Efficient Component Pricing Rule"?" Antitrust Bulletin, Vol. XL, (1995): 557-579.

Gans, J.S., and S.P. King. "Mobile Network Competition, Customer Ignorance and Fixed-to-Mobile Call Prices." Information Economics and Policy, Vol. 12 (2000): 301-327.

Gans, J.S., and S.P. King. “Using 'Bill and Keep' Interconnect Arrangements to Soften Network Competition." Economics Letters, Vol. 71 (2001): 413-420.

Ghosal, V. "Competition in International Postal Markets: Should the Universal Postal Union's Anti-remail Provisions Be Repealed?" World Competition Law and Economics Review, Vol. 26 (2002): 205-222.

Hahn, J.-H. "Network Competition and Interconnection with Heterogeneous Subscribers." International Journal of Industrial Organization, Vol. 22 (2004): 611-631.

Hermalin, B. and M. Katz. "Network Interconnection with Two-Sided User Benefits." Mimeo, UC Berkeley, 2001. 
Hermalin, B. and M. Katz. "Sender or Receiver: Who Should Pay to Exchange an Electronic Message?" Rand Journal of Economics, Vol. 35 (2004): 423448.

Jeon, D.S. "A Simple Access Pricing Rule to Achieve the Ramsey Outcome for Interconnected Networks." UPF Discussion Paper 808, 2005.

Jeon, D.S., J.J. Laffont and J. Tirole. "On the "Receiver-Pays" Principle." Rand Journal of Economics, Vol. 35 (2004), pp. 85-110.

Laffont, J.J., S. Marcus, P. Rey and J. Tirole. "Internet Interconnection and the Off-Net-Cost Pricing Principle", Rand Journal of Economics, Vol. 34 (2003): $370-390$.

Laffont, J.J., P. Rey and J. Tirole. "Network Competition I: Overview and Nondiscriminatory Pricing." Rand Journal of Economics, Vol. 29 (1998a): 1-37.

Laffont, J.J., P. Rey and J. Tirole. "Network Competition II: Price Discrimination." Rand Journal of Economics, Vol. 29 (1998b): 38-56.

Laffont, J.J. and J. Tirole. Competition in Telecommunications, MIT, 2000.

Mialon, S. H. "Pricing Access in Network Competition." Journal of Regulatory Economics, Vol. 31 (2007): 109-123.

OECD. "Access pricing in telecommunications." http://www.oecd.org/dataoecd/26/6/27767944.pdf. Paris, 2004.

Rochet, J.C. and L.A. Stole. "Nonlinear Pricing with Random Participation." Review of Economic Studies, Vol. 69 (2002): 277-311.

Salop, S. "Monopolistic Competition with Outside Goods." Bell Journal of Economics, Vol. 10 (1979): 141-156.

Sibley, D.S., M.J. Doane, M.A. Willams and S-Y Tsai. "Pricing Access To a Monopoly Input." Journal of Public Economic Theory, Vol. 6 (2004) pp. 541-555.

Stennek, J. and T.P. Tangerås. "Competition vs. Regulation in Mobile Telecommunications", mimeo RIIE. 2006.

Valletti, T.M. and C. Cambini. "Investments and Network Competition." Rand Journal of Economics, Vol. 36 (2005): 446-467. 
Willig, R. "The Theory of Network Access Pricing," in Issues in Public Utility Regulation, ed. by H. Trebing. Michigan State University Press, East Lansing, MI. 1979.

Wright, J. "Access Pricing under Competition: An Application to Cellular Networks." Journal of Industrial Economics, Vol. 50 (2002): 289-315. 